University of Nebraska - Lincoln

DigitalCommons@University of Nebraska - Lincoln

USDA National Wildlife Research Center - Staff Publications
U.S. Department of Agriculture: Animal and Plant Health Inspection Service

2013

\title{
As clear as mud: A critical review of evidence for the ecological roles of Australian dingoes
}

\author{
Benjamin L.R. Allen \\ University of Queensland, benjamin.allen@daff.qld.gov.au \\ Peter J.S. Fleming \\ Vertebrate Pest Research Unit \\ Lee R. Allen \\ Robert Wicks Pest Animal Research Centre \\ Richard M. Engeman \\ USDA-APHIS-Wildlife Services, s_r100@yahoo.com \\ Guy Ballard \\ Vertebrate Pest Research Unit, guy.ballard@dpi.nsw.gov.au
}

See next page for additional authors

Follow this and additional works at: https://digitalcommons.unl.edu/icwdm_usdanwrc

Allen, Benjamin L.R.; Fleming, Peter J.S.; Allen, Lee R.; Engeman, Richard M.; Ballard, Guy; and Leung, Luke K.-P., "As clear as mud: A critical review of evidence for the ecological roles of Australian dingoes" (2013). USDA National Wildlife Research Center - Staff Publications. 1088.

https://digitalcommons.unl.edu/icwdm_usdanwrc/1088

This Article is brought to you for free and open access by the U.S. Department of Agriculture: Animal and Plant Health Inspection Service at DigitalCommons@University of Nebraska - Lincoln. It has been accepted for inclusion in USDA National Wildlife Research Center - Staff Publications by an authorized administrator of DigitalCommons@University of Nebraska - Lincoln. 


\section{Authors}

Benjamin L.R. Allen, Peter J.S. Fleming, Lee R. Allen, Richard M. Engeman, Guy Ballard, and Luke K.-P. Leung 
Review

\title{
As clear as mud: A critical review of evidence for the ecological roles of Australian dingoes
}

\author{
Benjamin L. Allen ${ }^{\mathrm{a}, *}$, Peter J.S. Fleming ${ }^{\mathrm{b}}$, Lee R. Allen ${ }^{\mathrm{c}}$, Richard M. Engeman ${ }^{\mathrm{d}}$, Guy Ballard ${ }^{\mathrm{e}}$, \\ Luke K.-P. Leung ${ }^{a}$
}

a School of Agriculture and Food Sciences, The University of Queensland, Gatton, Queensland 4343, Australia

${ }^{\mathrm{b}}$ Vertebrate Pest Research Unit, Department of Primary Industries, Orange, New South Wales 2800, Australia

${ }^{\mathrm{c}}$ Robert Wicks Pest Animal Research Centre, Biosecurity Queensland, Toowoomba, Queensland 4350, Australia

${ }^{\mathrm{d}}$ National Wildlife Research Centre, US Department of Agriculture, Fort Collins, CO 8051-2154, USA

${ }^{\mathrm{e}}$ Vertebrate Pest Research Unit, Department of Primary Industries, Armidale, New South Wales 2350, Australia

\section{A R T I C L E I N F O}

\section{Article history:}

Received 27 July 2012

Received in revised form 21 November 2012

Accepted 2 December 2012

\section{Keywords:}

Biodiversity conservation

Experimental design

Mesopredator release

Relative abundance indices

Threatened fauna

Trophic cascades

\begin{abstract}
A B S T R A C T
Top-predators have been reported to have an important role in structuring food webs and maintaining ecological processes for the benefit of biodiversity at lower trophic levels. This is thought to be achieved through their suppressive effects on sympatric mesopredators and prey. Great scientific and public interest surrounds the potential use of top-predators as biodiversity conservation tools, and it can often be difficult to separate what we think we know and what we really know about their ecological utility. Not all the claims made about the ecological roles of top-predators can be substantiated by current evidence. We review the methodology underpinning empirical data on the ecological roles of Australian dingoes (Canis lupus dingo and hybrids) to provide a comprehensive and objective benchmark for knowledge of the ecological roles of Australia's largest terrestrial predator. From a wide variety of methodological flaws, sampling bias, and experimental design constraints inherent to 38 of the 40 field studies we assessed, we demonstrate that there is presently unreliable and inconclusive evidence for dingoes' role as a biodiversity regulator. We also discuss the widespread (both taxonomically and geographically) and direct negative effects of dingoes to native fauna, and the few robust studies investigating their positive roles. In light of the highly variable and context-specific impacts of dingoes on faunal biodiversity and the inconclusive state of the literature, we strongly caution against the positive management of dingoes in the absence of a supporting evidence-base for such action.
\end{abstract}

(c) 2012 Elsevier Ltd. All rights reserved.

\section{Contents}

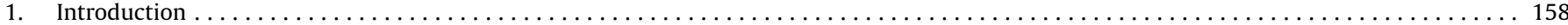

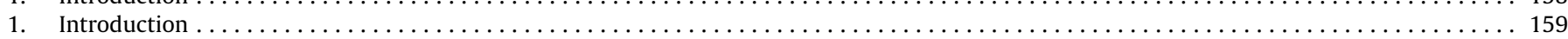

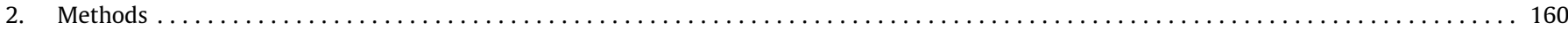

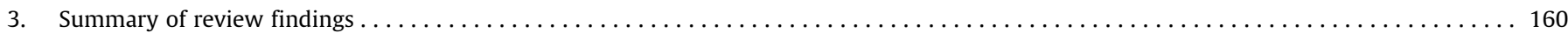

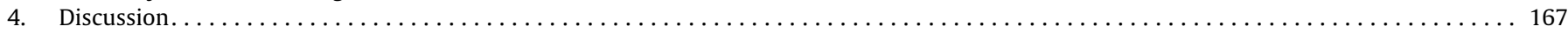

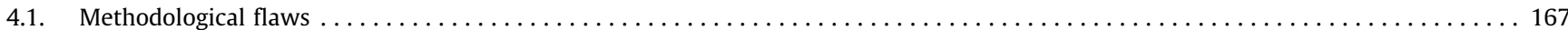

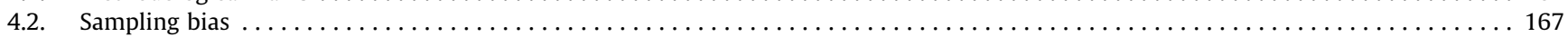

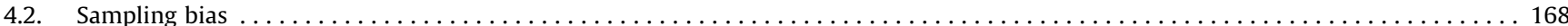

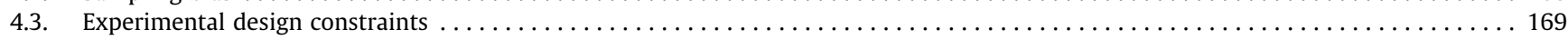

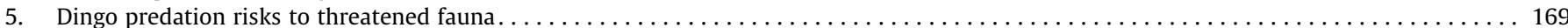

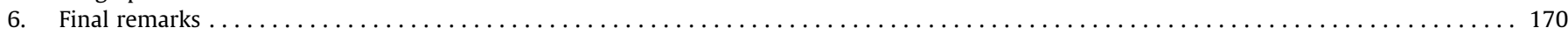

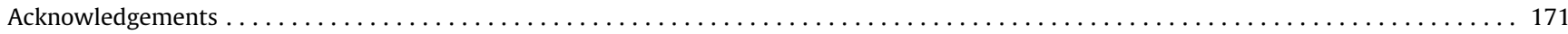

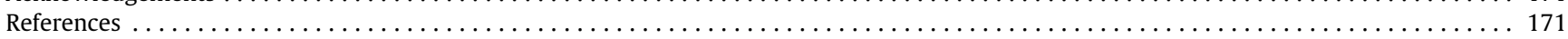

* Corresponding author. Present address: Robert Wicks Pest Animal Research Centre, Biosecurity Queensland, Toowoomba, Queensland 4350, Australia.

E-mail address: benjamin.allen@daff.qld.gov.au (B.L. Allen). 


\section{Introduction}

A wide variety of apex predators have been reported to have structuring roles in many ecosystems (Terborgh and Estes, 2010). Through direct (e.g. predation) and indirect (e.g. competition and fear) effects on sympatric carnivore and herbivore species, apex predators might limit, suppress or regulate mesopredators and prey and might even promote vegetation growth (e.g. Ripple and Beschta, 2012, but see Mech, 2012). Large terrestrial predators (e.g. lions Panthera leo, bears Ursus sp., or grey wolves Canis lupus) often have net beneficial effects on ecosystems (e.g. Levi and Wilmers, 2012; Miller et al., 2012). Small predators (e.g. feral cats Felis catus or black rats Rattus rattus) often have detrimental effects (e.g. Courchamp et al., 2000; Mifsud and Woolley, 2012). Owing to their flexible feeding, breeding and social ecology, medium-sized predators (e.g. dingoes Canis lupus dingo and hybrids, coyotes Canis latrans, or red foxes Vulpes vulpes) often have mixed effects depending on a range of context-specific factors, such as faunal assemblage or habitat complexity (e.g. Fleming et al., 2012; Soulé et al., 2005). Grey wolves are arguably the most discussed toppredator. Mech (2012) recently reviewed the available data on the ecological roles of wolves, showing that although much has been made of studies reporting the positive ecosystem services of wolves, plausible and important alternative explanations have not been addressed, and the relevant literature is far from being conclusive. In this critical review, we similarly evaluate the evidence-base for the ecological roles of Australian dingoes, the most closely related canid derived from wolves by humans several millennia ago (Fleming et al., 2012).

Dingoes are a widespread and typically common medium-sized $(\sim 12-20 \mathrm{~kg})$ terrestrial predator associated with neutral, positive and/or negative effects on economic, environmental and/or social values at different times and places (Corbett, 2001b; Fleming et al., 2012). Ignoring the important ecological roles of humans as apex predators, dingoes are the largest mammalian predator on the Australian mainland. Early studies of dingoes were often motivated by a desire to mitigate their well-known negative impacts on livestock (e.g. sheep, goats and cattle). In recent years, studies focused on the biodiversity benefits of dingoes have received much attention in the popular media (Table 1), fuelled by a proliferation of scientific reports claiming to provide evidence for their positive ecological roles.

Such reports typically argue that dingoes entrain trophic cascades by suppressing smaller foxes and feral cats and/or indirectly 'protecting' prey from mesopredator predation (e.g. Letnic et al., $2012 \mathrm{~b}$ ). The suppressive effects dingoes can have on native and introduced herbivores are also promoted. Importantly, and dissimilar to the top-predator guilds on every other continent, the three largest mammalian predators on the Australian mainland - dingoes, red foxes, and feral cats - are each relatively small and exotic species (Johnson, 2006). These three predators may not yet have had sufficient evolutionary time to adjust to each others' presence in the Australian context of new and still-changing landscapes and prey assemblages. These factors mean that the roles of dingoes are unlikely to be synonymous with those of top-predators on other continents (Allen, 2012b; Fleming et al., 2012).

Similar to the situation Mech (2012) described for wolves, a variety of ecological roles and functions have been attributed to dingoes, and the expected effects that hybridisation and lethal control has on these functions have been expressed (Table 1). Many studies supporting these perceptions have culminated in calls for a radical shift in the generally negative approach to dingo management towards their widespread positive management (i.e. cessation of lethal control and/or active restoration; e.g. Carwardine et al., 2011; Dickman et al., 2009; Johnson, 2006; Ritchie et al., 2012; Wallach et al., 2009b). Such calls have understandably raised substantial debate among ecologists, conservation biologists, wildlife managers, livestock producers and other stakeholders.

Much of the scientific dialogue has focused on the merits and reliability of the data in specific studies advocating a particular viewpoint, where two primary streams of debate are presently apparent (see previous reviews, replies and responses, in chronological order, by (1) Allen et al., 2011a; Letnic et al., 2011; Allen et al., 2011b; and Glen, 2012; and also by (2) Fleming et al., 2012; Johnson and Ritchie, in press; and Fleming et al., in press). Despite this, all ecologists share the view that more experimental data are needed to advance the discussion (e.g. Allen et al., 2012a; Visser et al., 2009). That trophic cascades occur is wellestablished (Estes et al., 2011; Terborgh and Estes, 2010), but whether or not their outcomes can be attributed to dingoes or their lethal control is the question here. In this study we do not attempt to repeat or review the debate so far. Rather, we provide a comprehensive, extensive and objective evaluation of the empirical data underpinning current knowledge and perceptions of dingoes' ecological roles as a benchmark to enhance future discussion. We focus primarily on studies that investigate predator population dynamics by estimating population abundances, exploring three key themes: (1) methodological flaws (previously reviewed in part

Table 1

Claims made by popular media and websites about dingoes' ecological roles.

Intact (not lethally controlled) populations are needed for dingoes to be effective in their roles ${ }^{\mathrm{a}, \mathrm{f}, \mathrm{i}}$

Dingoes suppress mesopredators, reducing fox and/or cat densities or distribution ${ }^{\mathrm{b}, \mathrm{c}, \mathrm{e}, \mathrm{f}, \mathrm{g}, \mathrm{h}, \mathrm{i}}$

Dingoes improve biodiversity, increasing small mammals or other threatened fauna ${ }^{\mathrm{b}, \mathrm{c}, \mathrm{e}, \mathrm{f}, \mathrm{h}, \mathrm{i}}$

Dingoes suppress kangaroos, wallabies, emus, goats, rabbits and/or pigs ${ }^{\text {c,d,e,f,g,h,i }}$

Dingoes regenerate or increase vegetation ${ }^{\mathrm{c}, \mathrm{e}, \mathrm{f}, \mathrm{h}, \mathrm{i}}$

Dingoes improve habitat for small mammals, reptiles and birds $\mathrm{s}^{\mathrm{e}, \mathrm{f}}$

Dingoes reduce total grazing pressure ${ }^{\mathrm{e}, \mathrm{f}}$

Dingoes select old, weak or sick prey and maintain a healthy prey population, ${ }^{\mathrm{c}, \mathrm{i}}$

Only pure dingoes (not hybrids) are trophic regulators, purity is ecologically important ${ }^{\text {h }}$

Both pure and hybrid dingoes are trophic regulators, purity is ecologically unimportant ${ }^{\mathrm{c}, \mathrm{f}}$

Hybrid dingoes are more harmful to the environment than pure dingoes ${ }^{\mathrm{d}}$

\footnotetext{
a Alexander, 2009. Concerns heightening for Fraser Island's dingoes, Ecos Magazine, 151, October-November 2009, pp. 18-19.

b Foundation for Australia's Most Endangered Species (www.fame.org.au/success, accessed 9th June 2012).

c Harriman, 2012. Introducing the dingo, the Australian Lion King, Australian Wildlife Secrets, 1(6), pp. 10-15.

d Davidson, 2004. The great dingo dilution, Ecos Magazine, 112, January-March 2004, pp. 10-12.

e de Blas, 2009. The dingoes role revitalised, Ecos Magazine, 147, February-March 2009, pp. 12-13.

${ }^{f}$ Levy, 2009. The dingo dilemma, Bioscience Magazine, 59 (6), June 2009, pp. 465-469.

g Millen, 2006. Call for more dingoes to restore native species, Ecos Magazine, 133, October-November 2006 , p. 5.

h Australian Dingo Conservation Association (www.dingoconservation.org.au, accessed 9th June 2012).

i Western Australian Dingo Association (www.wadingo.com, accessed 9th June 2012).
} 
by Allen et al., 2011a), (2) sampling bias, and (3) the inherent inferential limitations of various experimental designs. We also briefly discuss some negative and positive effects of dingoes on biodiversity, before summarising the present state of the relevant literature.

\section{Methods}

To focus our review on studies of predator interactions, we searched for all recent (since 1995) studies that used passive tracking indices to make inferences about the effects of dingoes on foxes, cats and/or threatened fauna. Passive tracking indices of relative abundance (or relative activity) have become the standard field technique used in Australia for assessing terrestrial predator populations to the point where almost all studies of predator population dynamics are based on such indices. However, the use of camera-trapping indices are becoming increasingly common (Meek et al., 2012). Passive tracking indices differ from active tracking indices which use food bait or some other form of attractant in attempts to lure animals towards the tracking station. Such methods are typically used in targeted assessments of poisonedbait attractiveness, palatability or uptake by predators (e.g. Allen et al., 1989; Glen and Dickman, 2003). Studies of this type have been critically reviewed elsewhere (Reddiex and Forsyth, 2006; Reddiex et al., 2006). In this critical review of dingo-related studies that used passive tracking indices, three international databases (Web of Science, Zoological Record and CSIRO Online) were accessed and searched using the following terms:

For Web of Science and Zoological Record:

- Dingo OR wild dog AND fox.

- Dingo OR wild dog AND cat.

- Dingo AND mesopredator.

For CSIRO Online:

\section{- Dingo (in 'Abstract' only).}

After removing duplicates, studies that used active tracking plots (e.g. Eldridge et al., 2000 or Mitchell and Banks, 2005) or simply compared indexing techniques (such as Allen et al., 1996a or Read and Eldridge, 2010) were also excluded. This was done to avoid studies that did not focus on dingo-mesopredator or dingo-prey interactions (in the case of bait efficacy studies) and those that were an experimental exercise in method development (in the case of technique comparisons). Such studies are relevant to our discussion but are outside its scope. To the remainder we added as many other track-based studies of dingoes that we were aware of, which were sourced from book chapters, conference papers, reference lists in the reports obtained from database searches, and publically available peer-reviewed theses or technical reports derived from datasets analysed in studies obtained from searches. Some different reports originating from the same datasets were combined for evaluation here to avoid either over- or under-stating the reliability of the available literature. Combining studies in this way was not done in cases where portions or all of the same dataset were analysed and reported separately in clearly different ways. Ultimately, 40 dingo-related studies published between January 1995 and November 2012 that used passive tracking indices were assessed (Table 2).

We did not attempt to explore the variety of statistical approaches used to subsequently analyse the data collected in the studies assessed, but rather limit the scope of our critique to three practical issues relating to the actual collection and reliable uses of the available tracking plot data. These were:
1. Methodological flaws (e.g. invalid seasonal and/or habitat comparisons, and violated assumptions).

2. Sampling bias (e.g. the implications of small spatial and/or temporal scales on results).

3. Experimental design constraints (e.g. the inherent limitations to the inferential ability of different experimental designs).

This was done to focus on the type of data collected (and available) and not the way the results were subsequently analysed or interpreted. Hence, and unlike other literature reviews on dingoes' roles, ours does not address what each study has purported to show, but how each study has purported to show it. Understanding the applied methodologies and limitations of the currently available literature is fundamental to substantiating the claims made about dingoes' ecological roles from this literature. The three issues we discuss centre on the implications of Engeman (2005; the first issue), Mahon et al. (1998; the second issue) and Hone (2007; the third issue), although a wide variety of other authors and texts also discuss the same issues (e.g. Caughley and Sinclair, 1994; Krebs, 2008). We use the definitions outlined in Table 1.2 of Hone (2007) to define the types of experimental designs and their corresponding levels of inferential ability. Thus, the treatment and niltreatment areas in a 'classical experiment' are randomised and replicated, are randomised only in an 'unreplicated experiment', are not randomised in a 'quasi-experiment', and are neither randomised nor replicated in a 'pseudo-experiment'. Studies without both treatment and nil-treatment areas are only observational in nature and have very poor inferential ability (Hone, 2007; Platt, 1964).

We note that the first issue was reviewed in Allen et al. (2011a), but only for 20 studies. The second and third issues have received little attention among those involved in dingo research and management (but see Glen et al., 2007). Thus, the review of Allen et al. (2011a) discussed only one (of three) issues for only half of the studies assessed here. In addition to what is provided in the present critical review, additional referencing and discussion of knowledge gaps, practical constraints to positive dingo management, policy and practice implications, and research priorities are discussed in Allen et al. (2012a), from which this report has been extracted and refined.

\section{Summary of review findings}

Of the 40 studies considered (Table 2), 15 (38\%) and 16 (40\%) of them are potentially weakened by habitat and seasonal confounding, while 12 (30\%) made unsupported and/or invalid assumptions. Nineteen (48\%) studies made at least one of these methodological flaws. Spatial scale varied considerably. Some studies were conducted within a $\sim 10 \mathrm{~km}^{2}$ area (e.g. Lundie-Jenkins et al., 1993; Moseby et al., 2006), within fenced enclosures (i.e. Moseby et al., 2012) or on small offshore islands (i.e. Allen et al., 1998), while others sampled within combined treatment areas in excess of $22,000 \mathrm{~km}^{2}$ (i.e. Allen, 2012b). The duration of nine studies (23\%) was less than $1 \mathrm{yr}$ (e.g. Fillios et al., 2010; Letnic et al., 2009a; Newsome et al., 2001; Wallach et al., 2009a), with an additional nine studies (23\%) lasting no more than 2 yrs (Table 2). Approximately two-thirds of studies were conducted in 3 yrs or less, and only one study was conducted for longer than 10 yrs (i.e. Arthur et al., in press; 28 yrs). Only one study undertook a classical experiment on dingoes (i.e. Allen, 2012b), and three more undertook unreplicated experiments (i.e. Allen et al., 1998; Allen, 2005; Eldridge et al., 2002). Hence, only four studies (10\%) were true experiments potentially capable of demonstrating cause and effect, whereas most of the remainder were either quasi- or pseudo-experimental in nature (Table 2 ). In passing, we note also that only $20 \%$ of studies 
Table 2

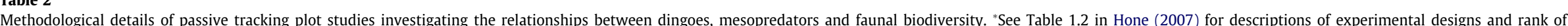

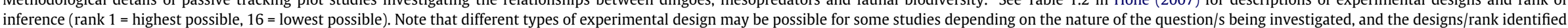

here represent the highest level of design possible from the data collected.

\begin{tabular}{|c|c|c|c|c|c|c|}
\hline & Reference & Study topic (climate) & Methodological strengths & Methodological weaknesses & $\begin{array}{l}\text { Spatial scale per site and } \\
\text { sampling effort }\end{array}$ & $\begin{array}{l}\text { Experimental } \\
\text { design (highest } \\
\text { rank of inference)* }\end{array}$ \\
\hline 1 & Allen, 2012b & $\begin{array}{l}\text { The effect of dingo control on } \\
\text { dingoes (arid) }\end{array}$ & $\begin{array}{l}\square \text { Manipulative experiment } \\
\square \text { BACI design } \\
\square \text { Random allocation of treatments } \\
\square \text { Treatment replication at some sites } \\
\square \text { Time-series data }\end{array}$ & $\begin{array}{l}\square \text { Baiting intensity varied within } \\
\text { treatments between replicates }\end{array}$ & $\begin{array}{l}\square 50 \text { plots over } 50 \mathrm{~km}(\times 2) \\
\square 6-10 \text { counts at } 4 \text { sites over } \\
2-4 \text { yrs }\end{array}$ & $\begin{array}{l}\text { Classical } \\
\text { experiment (1) and } \\
\text { Unreplicated } \\
\text { experiment (3) }\end{array}$ \\
\hline \multirow[t]{3}{*}{2} & $\begin{array}{l}\text { Allen et al., } 1998 \text { (see also Allen } \\
\text { et al., 1996b) }\end{array}$ & $\begin{array}{l}\text { The effectiveness of dingoes } \\
\text { introduced to an island to eradicate } \\
\text { feral goats (sub-tropical) }\end{array}$ & $\square$ Manipulative experiment & $\begin{array}{l}\square \text { Plots monitored on only one island (of the } \\
\text { two) }\end{array}$ & $\square 16-21$ plots over $21 \mathrm{~km}$ & $\begin{array}{l}\text { Unreplicated } \\
\text { experiment ( } 3 \text { ) }\end{array}$ \\
\hline & & & $\begin{array}{l}\square \text { Dingoes introduced, rather than } \\
\text { removed }\end{array}$ & $\begin{array}{l}\square \text { Feral goats aerially culled on the 'nil } \\
\text { treatment' island midway through the } \\
\text { study }\end{array}$ & $\square 5$ counts over 3 yrs & \\
\hline & & & $\square$ Time series data & & & \\
\hline \multirow[t]{2}{*}{3} & Allen and Gonzalez, 2000 & $\begin{array}{l}\text { The responses of dingoes and other } \\
\text { wildlife to a large and intensive } \\
\text { military exercise (sub-tropical) }\end{array}$ & $\square$ Manipulative experiment & $\square$ Non-independence between treatments & $\square 25-52$ plots over $25-52 \mathrm{~km}$ & $\begin{array}{l}\text { Quasi-experiment } \\
\text { type III ( } 7 \text { ) }\end{array}$ \\
\hline & & & $\begin{array}{l}\square \text { BACI design } \\
\square \text { Four different treatments assessed }\end{array}$ & & $\square 4$ counts at 1 site over $1 \mathrm{yr}$ & \\
\hline \multirow[t]{3}{*}{4} & Allen, 2005 & $\begin{array}{l}\text { The effect of dingo control on beef } \\
\text { cattle (monsoonal tropics and semi- } \\
\text { arid) }\end{array}$ & $\square$ Manipulative experiment & $\square$ No replication at individual sites & $\square 50$ plots over $50 \mathrm{~km}(\times 2)$ & $\begin{array}{l}\text { Unreplicated } \\
\text { experiment ( } 3 \text { ) }\end{array}$ \\
\hline & & & $\square$ BACI design & & $\begin{array}{l}\square 7-19 \text { counts at } 3 \text { sites over } \\
3-4 \text { yrs }\end{array}$ & \\
\hline & & & $\begin{array}{l}\square \text { Random allocation of treatments } \\
\square \text { Time-series data }\end{array}$ & & & \\
\hline \multirow[t]{4}{*}{5} & Allen, 2006 & $\begin{array}{l}\text { The effectiveness of dingo control } \\
\text { campaigns (semi-arid) }\end{array}$ & & $\square$ Non-random allocation of treatments & $\begin{array}{l}\square 92-133 \text { plots over } 92- \\
133 \mathrm{~km}\end{array}$ & $\begin{array}{l}\text { Quasi-experiment } \\
\text { type I (5) }\end{array}$ \\
\hline & & & $\square$ Multiple properties surveyed & $\square$ Non-independence between treatments & $\begin{array}{l}\square 16-23 \text { counts at } 3 \text { sites over } \\
2-3 \text { yrs }\end{array}$ & \\
\hline & & & $\square$ Temporally intensive sampling & $\begin{array}{l}\square \text { Baiting intensity varied between } \\
\text { properties within-treatments }\end{array}$ & & \\
\hline & & & $\square$ Time-series data & & & \\
\hline \multirow[t]{2}{*}{6} & Allen, 2012d & $\begin{array}{l}\text { Interactions between dingoes, } \\
\text { livestock guardian dogs, and other } \\
\text { wildlife (semi-arid) }\end{array}$ & $\square$ Mensurative study & $\square$ Short-term study & $\square 42-62$ plots over $42-62 \mathrm{~km}$ & $\begin{array}{l}\text { Quasi-experiment } \\
\text { type III (7) }\end{array}$ \\
\hline & & & $\begin{array}{l}\square \text { Treatment and nil-treatment areas } \\
\square \text { Measured movements and } \\
\text { behavioural interactions of dingoes and } \\
\text { livestock guardian dogs in addition to } \\
\text { passive tracking indices }\end{array}$ & $\square$ Non-randomised treatments & $\square 3$ counts at 2 sites over $1 \mathrm{yr}$ & \\
\hline \multirow[t]{2}{*}{7} & Arthur et al., in press & $\begin{array}{l}\text { Successional change in vegetation } \\
\text { and animal abundances after } \\
\text { wildfire (temperate) }\end{array}$ & $\square$ Mensurative study & $\begin{array}{l}\square \text { Used binary observations over potentially } \\
\text { continuous measures }\end{array}$ & $\begin{array}{l}\square 45 \text { plots over } 18 \mathrm{~km} \text { and } 65 \\
\text { plots over } 26 \mathrm{~km}\end{array}$ & $\begin{array}{l}\text { Pseudo- } \\
\text { experiment type V } \\
\text { (13) }\end{array}$ \\
\hline & & & $\square$ Spatial replication of transects & $\square$ Transects pooled instead of separated & $\begin{array}{l}\square \text { Annual counts at } 1 \text { site for } \\
28 \text { yrs }\end{array}$ & \\
\hline
\end{tabular}


8 Augusteyn et al., 2010

The effect of dingo control on dingoes and bridled nailtail wallabies (semi-arid)

$9 \quad$ Brawata and Neeman, 2011

Predator distribution around waterpoints in the arid zone (arid)

Transformed sand plot index data

$\square$ Time-series data

$\square$ BACI design

$\square$ No nil-treatment areas

Manipulative experiment

$\square$ One study site only

$\square$ No nil-treatment area

$\square$ Time-series data

Measured demographic responses of prey

$\square$ Spatial replication of treatments

$\square$ Two indices of predators used

$\square$ Data confounded by habitat and seasonal effects

$\square$ Used binary observations over potentially $\quad \square 2$ counts at 5 sites over 3 yrs continuous measures

$\square$ Two experiments in one, but analysed together

The effects of dingo control on

$\square$ BACI design

Sand plo

$\square$ Non-random allocation of treatments dingoes, foxes and cats (arid)

$\square$ Three indices of predators attempted

$\square$ Time-series data

The influence of habitat on small

$\square$ Mensurative study

mammals (temperate)

$\square$ Standardised design

The effects of cane toads on native $\quad \square$ BACI design fauna (monsoonal tropics)

$\square$ Three treatments

$\square$ Different indices for some species (arid)
Reintroduction success of native mammals following predator control (see also Burrows et al., 2003) $\square$ Two measures of predators used
15 plots over $20 \mathrm{~km}(\times 2)$ and 20 scent stations over

Quasi-experiment

$20 \mathrm{~km}(\times 2)$

20-35 plots over 4-7 km

$\square 2$ counts at 13 sites over

7 yrs

transects

25 counts at 1 site over

$10 \mathrm{yrs}$

Pseudo-

experiment type

VII (15)

20 counts at 1 site over

5 yrs

$\square 25$ plots over $5 \mathrm{~km}$

$\square 4$ counts at 1 site over 2 yrs

uasi-experimen type I (5)

Pseudo- experiment type $V$ (13)

$\square 0 \mathrm{~km}$ tracking transect

Quasi-experiment type IV (8)

Quasi-experiment type III (7) $\square$ Invalid assumptions when calculating the activity of predators

$\square$ Data confounded by seasonal differences

in predator activity

Onalid comparisons between species

$\square$ One index technique (cyanide bait

uptake) renoved individuals from the

population

$\square$ Data confounded by seasonal differences

in predator activity

$\square$ Invalid comparisons between habitats

$\square$ Sand plot index data untransformed

$\square$ Used binary observations over potentially continuous measures

$\square$ Sand plot index data untransformed

$\square$ Invalid assumptions when calculating the activity of predators

$\square$ Predators in 'nil-treatment' areas sampled using an index technique (letha cyanide bait uptake) that removed individuals from the population

$\square$ 'Nil-treatment' area relocated during the course of the study

$\square$ Cyanide sampling technique biased

towards dingoes and foxes

$\square$ Only 1 (of 2) treatment was sampled on 7

of the 8 surveys

$\square 8$ surveys at 1 site over 4 yrs 

(temperate)

15 Corbett, 1995

16 Edwards et al., 2002

17 Edwards et al., 2002

18 Edwards et al., 2002b

20 Fillios et al., 2010

21 Fleming et al., 1996 (see also Fleming, 1996)

22 Johnson and VanDerWal, 2009 (using data originally from Catling and Burt, 1995b; Newsome et al., 1983)

Relationships between dingoes, water buffalo and feral pigs (monsoonal tropics) (arid)

The effect of rabbit warren ripping on wildlife (arid)

The effect of Rabbit Haemorrhagic Disease on wildlife (arid)

The effect of dingo control on dingoes and wildlife (arid) kangaroos (arid)

The effects of dingo control on dingoes (temperate)

Dingoes ability to limit fox abundance (temperate)

$\square$ Not all survey results are reported

$\square$ No analyses undertaken

$\square$ Used binary observations over potentially $\quad \square 75-125$ plots over 19- $\quad$ Quasi-experiment continuous measures

$\square 19$ counts at 1 site over

$\square$ Spatial replication of treatments and $\quad \square$ Assumed independence between sand

$\square$ Time-series data

Habitat selection by dingoes and cats $\quad \square$ Mensurative study

Relationships between dingoes and $\quad \square$ Spatial replication of treatments transects

$\square$ BACI design

$\square$ Independent indices of some species

$\square$ Calibrated pig and dingo indices with mark-recapture estimates and total

counts

$\square$ Time-series data

$\square$ Standardised design

$\square$ Mensurative study

$\square$ Standardised design

$\square$ Manipulative experiment

$\square$ Two measures of predators used $\square$ Replication of sampling transects within treatments

$\square$ Used binary observations over potentially continuous measures

$\square 55$ plots over $400 \mathrm{~km}$

$\square 27$ counts at 1 site over 7

$\square$ Invalid assumptions when calculating the activity of predators

$25 \mathrm{~km}$ tracking transects $(\times 4)$

Psuedoexperiment type $\mathrm{V}$

$\square$ Data confounded by seasonal and habitat $\quad \square 9$ counts at 1 site over 3 yrs differences in predator activity

$\square$ Invalid assumptions whencalculating the activity of predators

$10 \mathrm{~km}$ tracking rectangle Quasi-experiment

type I (5)

ifferences in predator activity

$\square$ Baiting intensity varied between sites

$\square$ Invalid assumptions when calculating the activity of predators

$10 \mathrm{~km}$ tracking rectangle Pseudo( $\times 2$ at four sites) experiment type $V$ $(13)$

$\square$ Data confounded by seasonal and habitat $\quad \square 8$ counts at 6 sites over 2 yrs differences in predator activity

Data influenced by rabbit warren rippin $\square$ Data influence

$\square$ Invalid assumptions when calculating the activity of predators

$10 \mathrm{~km}$ tracking transects $(\times 6)$

$\square 7$ counts at 3 sites over 3 yrs

Unreplicated experiment (3)

$\square$ Replication devalued by seasonally staggered indexing

$\square 25$ plots over $25 \mathrm{~km}(\times 2) \quad$ Quasi-experiment

$\square$ Data confounded by seasonal and habitat $\quad \square 1$ count at 6 sites over 1 yr type I (5)

and dingoes

$\square$ Sand plot incex

$\square$ Non-random allocation of treatments

$\square$ Abundance and activity potentially confounded

$120-270$ plots over 12

$27 \mathrm{~km}(\times 2)$

$\square 12$ counts at 1 site ove

3 yrs

$\square$ Data corrected for detection probability

$\square$ Source data from mensurative studies

$\square$ Source data confounded by seasonal and habitat differences in predator activity

From Newsome et al., 1983:

experiment type $\mathrm{V}$ (13)

$\square$ Large data set over wide spatial $\square$ Source data used binary observations 
over potentially continuous measures

$\square$ Invalid comparisons between species

$\square$ Sand plot index data untransformed

Relationships between dingo control, $\square$ Mensurative studies an dingoes and cats (monsoonal tropics) manipulative experiments

$\square$ Spatial replication of treatments reported

$\square$ Mensurative study temporally replicated

$\square$ Data transformed

$\square$ Time-series data

24 Koertner and Watson, 2005

The impact of dingo control on quolls $\square$ Uses two measures of efficacy (temperate)

25 Letnic et al., 2009a (a subset of Letnic et al., 2009b)

Dingoes' role in protecting dusky hopping-mice from predation by foxes and cats (arid)

Relationships between dingoes and wildlife (arid)

28 Lundie-Jenkins et al., 1993 staggered indexing
Relationships between dingoes and kangaroos (arid, semi-arid)

Relationships between hare-

wallabies and introduced mammals (arid) $\square$ Replication of treatment (individuals $\quad \square$ Index data untransformed exposed)

$\square$ Measured demographic and

behavioural responses of prey

$\square$ Spatial replication of treatments

$\square$ Replication devalued through seasonally staggered indexing

25-30 plots over $25-30 \mathrm{~km} \quad$ Quasi-experiment $(\times 2)$ type I (5)

$\square$ Different measures for hopping-mice and dingoes used

$\square$ Data influenced by seasonal and habitat differences in predator activity

$\square$ Spatial replication of treatments

$\square$ Different measures for wildlife and dingoes

$\square$ Effect size measured

$\square$ Replication devalued through seasonally

$\square$ Data influenced by seasonal and habitat differences in predator activity

$\square$ Used binary observations over potentially continuous measures

$\square$ Insensitive measures of grazing pressure used

Spatial replication of treatments

$\square$ Replication devalued through seasonally $\square$ Replication devalued through seasonally
staggered indexing

$\square$ 24-30 plots over 24-30 km Quasi-experiment $\square$ Simultaneous collection of dingo and kangaroo indices differences in predator activity

$\square$ Mensurative study

$\square 2$ counts at 1 site once

$\square 1$ count at 3 sites over $1 \mathrm{y}$

25 -30 plots over $25-30 \mathrm{~km} \quad$ Quasi-experimen

type I (5)

1 count at 8 sites over 2 yrs $\square 24-3$

Quasi-experin
type I (5)

$\square$ Used binary observations over potentially

1 count at 9 sites over 2 yrs

$\square$ Intensive plot coverage Simple plots over $26 \mathrm{~km}$ and 105

plots over $84 \mathrm{~km}$

$\square$ Repeated counts at 3 sites

for up to 9 yrs

From Catling and Burt, 1995b:

$\square$ 20-35 plots over $4-7 \mathrm{~km}$

$\square$ or 2 counts at 15 sites

over 7 yrs

30-50 plots over $30-50 \mathrm{~km}$ Pseudo-

$(\times 10) \quad$ experiment type

(9) and Quasi-

experiment type

(5)

$\square 3$ counts at 2 sites over 3 yrs 4 week

Quasi-experimen

type I (5) and

Pseudo-

(13)

continuous measures within a $\sim 10 \mathrm{~km}^{2}$ area $\quad$ observations (16 
31 Newsome et al., 2001

32 Pascoe, 201

33 Pavey et al., 2008

34 Pettigrew, 1993

35 Purcell, 2009

36 Southgate et al., 2007a,b

37 Wallach and O'Neill, 2009 (a

\section{$\square$ BACI design}

\section{$\square$ Individual animals identified \\ $\square$ Provides conclusive proof of \\ interspecific predation of foxes and cats \\ by dingoes}

Non-independence between plots

$\square 4$ counts at 1 site over $1 \mathrm{yr}$ $\square$ No details of dingo control program given $\square$ Very small spatial scale

$\square$ Used binary observations over potentially continuous measures

grid $(\times 2)$

Quasi-experiment

type II (6) or

experiment type VI

\section{$\square$ Very small spatial scale}

$\square$ Limited scale and applicability

$\square 15$ counts at 2 sites over 8 yrs

$\square 39$ plots interspersed inside Quasi-experiment a $37 \mathrm{~km}^{2}$ pen and 38 plots interspersed in a similar size type IV (8)

$\square$ Non-independence of treatments $\square$ Dingo activity trends not reported

$\square$ Incomplete analyses of sand plot data $\square$ Used binary observations over potentially continuous measures for some analyses

Fence effect on dingoes and wildlife $\quad \square$ Different measures for wildlife and (arid)

dingoes

Predator ecology and interactions (temperate)

$\square$ Mensurative study

$\square$ Two measures of dingoes used

$\square$ Spatial replication

Population dynamics of rodents and $\quad \square$ Mensurative study predators (arid)

$\square$ Different measures for wildlife and dingoes

Two measures of dingo abundance collected

The effect of dingo control on cats

$\square$ Demographic data on cats collected (arid)

$\square$ Two measures of predators used

Dingo purity, diet, activity and behaviour (temperate)

$\square$ Mensurative study

$\square$ Temporally intensive sampling

Bilby and predator distribution and fire (arid)

$\square$ Three different sampling strategies used

$\square$ Different measures of bilbies and predators

$\square$ Two measures of dingo abundance $\square$ Used binary observations over potentially $\square 31$ plots over $15 \mathrm{~km}$ continuous measures for some analyses

$\square$ Sand plot index data untransformed

$\square$ Invalid assumptions when calculating the activity of predators

8 counts at 3 sites over 2 yrs

$\square$ Invalid comparisons between species

$\square$ Merged sandplot and spotlighting dat

$\square$ Ambiguous description of site and methodology

$\square$ Data from both sampling measures apparently combined

Data from some treatments not reporte

$\square$ Used binary observations over potentially

$\square$ Sand plot index data untransformed

$\square$ Data influenced by seasonal and habitat differences in predator activity

$\square$ Used binary observations over potentially continuous measures

$\square$ Invalid assumptions when calculating the activity of predators

$\square$ Footprints assumed 'old' were excluded from occupancy analysis

$\square$ Data influenced by seasonal and habitat $\square$ Invalid comparisons between species $\square$ Ringed plots around 10 waterpoints $(\times 2)$

$\square 4$ counts at 1 site over $1 \mathrm{yr}$

$\square 10 \mathrm{~km}$ tracking transects $(\times 3)$

$\square$ Spatial scale unknown
$\sim 100 \mathrm{~km}$ of transect

$\sim 10 \mathrm{~km}$ of transect 3 yrs

$\square 25$ plots over $25 \mathrm{~km}(\times 2)$

$\square 26$ counts at 1 site over 2 yrs

$\square 10 \mathrm{~km}$ rectangle tracking transects $(\times 2)$

6-8 counts at 8 sites over 4 yrs

uasi-experiment type I (5)

Pseudoexperiment type (13)

Pseudo-

experiment type $V$ (13)

Quasi-experiment type IV (8)

(1)

experiment type V (13)

Quasi-experiment type I (5)

$\square$ 10-12 strip plots (500 m 


Methodological strengths

collected

subset of Wallach et al., 2010, $\quad$ kowaris (arid)

2009b)

38 Wallach et al., 2009a (a subset of Wallach et al... 2010, 2009b) footed rock wallabies and malleefowl from predation by foxes and cats (arid, semi-arid)

res of dingo abundance collected

$\square$ Large data set over wide spatial distribution

The effect of dingo control on pack structure and social stability (arid)

39 Wallach et al., 2009b

Two measures of dingo abundance

$\square$ Large data set over wide spatial distribution

The effect of dingo control on nvasive species (arid)

40 Wallach et al., 2010

Methodological weaknesses

patial scale per site and sampling effort

Experimental

design (highes

rank of inference)*

differences in predator activity

long), and 20 area plots ( 2 ha) type IV (8)

$\square$ Invalid assumptions when calculating the $\square 1$ count at 2 sites once

relative abundance, "Index of abundance",

and territorial activity of predators

$\square$ Data influenced by the presence of pet

dogs and people

$\square$ Multiplication of binary and continuous abundance measures

$\square$ Sand plot index data untransformed

$\square$ Small spatial scale

Data influenced by seasonal and habitat differences in predator activity

9-25 strip plots (500 m long), and 21-39 area plots (2 ha)

uasi-experimen type III (7)

$\square$ Invalid assumptions when calculating the $\square 1-2$ counts at 7 sites over relative abundance, "Index of abundance", and territorial activity of predators

$\square$ Data influenced by the presence of pet dogs and people

$\square$ Multiplication of binary and continuous abundance measures

$\square$ Sand plot index data untransformed

$\square$ Small spatial scale

$\square$ Data influenced by seasonal and habitat differences in predator activity

$1 \mathrm{yr}$ (2 ha)

Invalid assumptions when calculating the relative abundance, "Index of abundance" and territorial activity of predators

$\square$ Data influenced by the presence of pet dogs and people

$\square$ Multiplication of binary and continuous abundance measures

Sand plot index data untransformed

$\square$ Small spatial scale $\square$ Two measures of dingo abundance

$\square$ Data influenced by seasonal and habitat differences in predator activity

$10-12$ strip plots $(500 \mathrm{~m}$ long), and $20-40$ area plots

$\square$ Large data set over wide spatial distribution

$\square$ Invalid assumptions when calculating the $\square 1-3$ counts at 7 sites over relative abundance "Index of abundance" and territorial activity of predators by the presence of pet dogs and people

Multiplication of binary and continuous abundance measures

$\square$ Sand plot index data untransforme $\square$ Small spatial scale

Quasi-experiment
type III (7)
Quasi-experiment
type III (7)


were conducted in temperate ecosystems, and $69 \%$ of studies were conducted in arid or semi-arid areas. In short:

1. Nearly half of the relevant literature contained methodological flaws which render the reliability of the data collected uncertain. In many cases, it is not the technique that is weak, but it is the poor application of otherwise robust techniques that compromise the data collected (Allen, 2010). This is not to say that the conclusions of such studies are incorrect, but that the reader cannot evaluate whether they are or not because of the flaws.

2. Many studies were conducted over relatively small spatial and/ or temporal scales. Because of spatiotemporal variation in animal densities, behavioural avoidance of top-predators by mesopredators, and because most studies sample predators along roads, the results of many such studies may simply be artefacts of sampling bias.

3. The experimental designs of almost all studies are only observational or correlative, rendering their conclusions subject to a wide variety of plausible and competing alternative explanations. Such studies can only support statements such as 'dingoes might perform this role' instead of statements such as 'dingoes do perform this role', which can only be made reliably from the few studies with greater inferential capacity.

These results indicate that multiple studies contain multiple methodological weaknesses and limitations, preventing justifiable statements about the ecological roles of dingoes from such studies. It is also important to note that this conclusion is not so much about 'dingoes' as it is about 'methods', and these results would be similar had the study animal been any other sampled using passive tracking indices in the ways described. Our results also imply that publication outlet, research institution, media interest, or subsequent popularity and expert opinion is of little use as a guide to identifying the ecological roles of dingoes.

\section{Discussion}

\subsection{Methodological flaws}

Critical review of these flaws previously revealed that the data in $75 \%$ ( 15 of 20 ) of recent studies that sampled dingoes using sand plots on roads are potentially confounded by a variety of factors, including (but not limited to) invalid seasonal and habitat comparisons or unsupported assumptions (Allen et al., 2011a). Our more comprehensive review indicates that the prevalence of such flaws is lower, but still relatively common throughout the literature (Section 3). Most of the studies containing these flaws were published in respectable peer-reviewed journals, while many unpublished 'grey literature' reports do not contain these flaws (Table 2; see References).

Dingo activity on roads varies between seasons independent of their actual abundance (e.g. Allen et al., 2011a; Allen, 2009), which can lead to confounding and weakened inferences if not accounted for by the study design. For example, valid comparisons cannot be made between one site sampled in winter and another site sampled in summer, because observed activity differences are likely to be attributable to behavioural changes and not abundance changes. This issue may most easily be understood for ectothermic reptiles, which usually reduce their activity in winter. For dingoes and foxes, food availability and annual breeding cycles usually drive this variability (Corbett, 2001b; Saunders and McLeod, 2007).

Comparisons between different habitats may also be confounded due to varying detection probabilities associated with dif- ferent habitat types (Anderson, 2001; Engeman, 2005; MacKenzie et al., 2006). For example, even if abundance is equal across habitats, animals occupying landscapes with more difficult terrain may utilise roads (i.e. where sampling occurs) more frequently than animals occupying areas which allow more ubiquitous movements, with observed activity differences again potentially attributable to behavioural differences and not abundance differences. Moreover, different habitats often have different floral and faunal assemblages, geological, hydrological and ecological processes (e.g. Newsome et al., 2001), which may influence the way some species interact with sand plots placed on roads. Pooling across seasons or habitats may mask differences that could be more easily viewed if separated (see Allen, 2012b for an example).

A variety of assumptions, such as 'footprints of the same size and species $<500 \mathrm{~m}$ apart and heading in the same direction belong to the same individual' or 'old-looking footprints are $x$ days old' are also commonly made (Table 2 ) and undoubtedly false or violated (e.g. Edwards et al., 2002a; Eldridge et al., 2002; Southgate et al., $2007 a, b)$. The validity of such assumptions is also likely to vary throughout the year (Allen, 2009), and their violation may misrepresent dingo distribution or abundance. Other invalid assumptions ( such as ' $>1$ photo of a predator in $<10 \mathrm{~min}$ is the same individual predator' or 'dingo scat deposition rates vary little throughout the year') undermine the reliability of similar dingo-mesopredator studies that use other types of relative abundance indices (such as camera-trapping rates or scat indices) to sample and contrast dingo populations over multiple seasons and habitats (Allen, 2012c; but see Wallach et al., 2009b or Brook et al., 2012 for examples).

Although a wide variety of methodological weaknesses are evident (Table 2), violation of assumptions and confounding from variable seasons and/or habitats may be more important than other flaws, in that they could have greater ecological significance on the conclusions drawn (Allen et al., 2011a; Engeman, 2005). Fundamentally, indices are only useful when they are correlative of true abundance (Caughley, 1980; Pollock, 1995; Sutherland, 1996), and the presence of such flaws typically means that the relationship between observed indices and true abundances is unknowable. We note however, that accurate knowledge of absolute abundance is near impossible to acquire in the field, and we are not aware of any studies of dingoes that have calibrated sand plot activity data with absolute abundance values (because absolute abundance values have not been attainable). However, where the indexing principles outlined in Pollock (1995) or Engeman (2005) are strictly applied, researchers can acquire reliable estimates of relative abundance, the metric that underpins the vast majority of available field data on dingo population dynamics.

The use of inappropriate techniques or poor application of otherwise robust techniques reduces the extent to which such data can be used to make reliable statements about interspecific relationships. Inferences from any such studies will be seriously limited at best, and may be completely invalid at worst. Because $48 \%$ of studies have made such flaws (Table 2), much of the available sand plot data on dingoes might be considered unreliable (Allen et al., 2011a), rendering the popular perceptions drawn from these studies baseless (Table 1). Overturning this conclusion for any given study requires demonstration that either (1) the methodological flaws described were not made and/or (2) that if made, the data are somehow still reliable (Glen, 2012). Once collected, it is also rarely possible to un-confound the data using statistical procedures. As has been noted, 'you can't fix by analysis what you bungled by design' (Light et al., 1990). Others (Glen, 2012; Letnic et al., 2011; but see also Allen et al., 2011b) have questioned the importance of these flaws, but such is not the only issue undermining the evidence-base for dingoes' ecological roles. 


\subsection{Sampling bias}

An index is a measurement related to the actual variable in question and specific to the circumstances under which the data were collected. Importantly, animal populations are not usually distributed uniformly across the landscape but are instead clumped, producing areas of higher and lower abundance. Thus, studies conducted over small spatial scales may acquire severely biased results. For example, the areas sampled in Moseby et al. (2006) or Lundie-Jenkins et al. (1993) were very small $\left(\leqslant 10 \mathrm{~km}^{2}\right)$, which likely represents only a fraction of a dingo's home range in such systems (Allen, 2012a; Newsome, 2011). The observed relationships between species within such small areas may have limited applicability outside the areas sampled where animal abundances may be markedly different (e.g. Thomson, 1992). A small spatial scale is not a problem per se, but studies conducted at such scales must be careful not to unjustifiably extend their inferences beyond the area sampled. Those subsequently citing such studies must be careful to do the same in order not to inadvertently propagate misleading impressions of the studies cited.

Animal activity is also rarely distributed uniformly over temporal scales. Within a $24 \mathrm{~h}$ period, animals may exhibit diurnal, nocturnal or crepuscular behavioural cycles which prevent reliable comparisons of index values from one time period to another. This may be most easily understood for birds where, for example, observations collected from one area in the early morning should not be compared to observations collected from another area at noon. Many of these considerations essentially amount to issues of detection probability, and have been discussed in greater detail elsewhere (e.g. Anderson, 2001; Johnson, 2008; MacKenzie et al., 2006; Pollock et al., 2002). The same principles apply to abundance indexing and population estimation using almost any technique, including camera trap or scat indices (Allen, 2012c) or population estimates derived using mark-recapture, aerial surveys, distance sampling of actual observations or signs, occupancy modelling or track transects (e.g. Engeman, 2005, 2003; Johnson, 2008; Pollock, 1995).

The highest activity periods for top-predators usually coincide with the highest activity periods of their preferred prey and mesopredators usually avoid top-predators during these times at fine scales (e.g. Atwood et al., 2011; Hayward and Slotow, 2009; Mitchell and Banks, 2005; Ramesh et al., 2012). Because mesopredators typically seek to avoid encountering top-predators (i.e. fear effects), mesopredator activity is likely to be lower at times and in places with higher top-predator activity. This has important implications for many dingo studies that were conducted over restricted temporal scales, such as snap-shot or single-sample studies that survey animals over a few days only (e.g. Brook et al., 2012; Letnic et al., 2009a,b; Wallach et al., 2009a). If dingo activity is high on those days, mesopredator activity would be expectedly lower, or vice versa. Such temporally limited data is silent on the ability of dingoes to suppress or exclude mesopredator abundances over larger time scales because mesopredators may simply have been avoiding the sampling area on those days.

Conducting successive surveys over slightly longer timeframes, such as three or four surveys over $1 \mathrm{yr}$ (e.g. Allen, 2012d; Fillios et al., 2010; Newsome et al., 2001), may also be affected because periods of high or low top-predator activity may endure for several months (e.g. Allen, 2012a, 2009; Allen et al., 2011a; Purcell, 2009). This is important for studies such as Lundie-Jenkins et al. (1993) or Pettigrew (1993), which have been mistakenly viewed as positive population responses of mesopredators to single dingo control events (e.g. Glen et al., 2007; Johnson and Ritchie, in press; Letnic et al., 2012b). Again, however, such observations would be expected given that mesopredators may increase their use of tracks once the landscape of fear has been altered without necessarily altering their actual abundance or ecological impact. For example, the immediate burst of $\sim 700$ cats observed by Pettigrew (1993) within a few months after the shooting of $\sim 50$ dingoes during a long-haired rat (Rattus villosissimus) plague was characterised by adult cats, suggesting (at best) a temporary behavioural response by extant cats but not a numerical response.

Temporally restricted data cannot be reliably used as evidence that dingo control increases the abundance of mesopredators (especially predators that only breed once annually, such as foxes; Saunders and McLeod, 2007) unless the results can be adjusted for seasonal effects by incorporating data from a comparable nil-treatment area. Even if this was done, subsequent compensatory effects (such as increased mortality or dispersal of mesopredators) may later return the system to pre-control levels within a year or so, which means that any numerical or functional responses may be short-lived. Even over several years, a sampling strategy which focuses on landscape features where dingoes are expected to be more active (such as roads and trails) are also likely to be biased towards the detection of dingoes and less sensitive (but in no way insensitive; Allen, 2005) at detecting foxes or cats (Mahon et al., 1998; but see also Pollock, 1995). Such issues of bias on sand plots are intended (in order to obtain more track records of the predator of interest), and render interspecific comparisons of index values inappropriate (Engeman, 2005). This bias is typically overcome by sampling populations over larger spatial and/or temporal scales.

All studies identified in Table 2 have sampled predators for only a few days at a time during each survey, meaning that the results from each individual survey, in isolation, are subject to such bias. This is an important weakness for the short-term studies identified (e.g. Letnic et al., 2009a; Wallach and O'Neill, 2009), but when surveys are repeated over multiple seasons or years, population trends defined by the index values over time can be valid given appropriate study design and data analyses (Engeman, 2005). For example, fox activity on sand plots may be much lower than those of dingoes for any (or every) given survey (possibly as a result of sampling bias), but when surveyed repeatedly over longer timeframes, correlations between dingo and fox population trends can be confidently compared (e.g. Arthur et al., in press; Claridge et al., 2010). When predator abundance is further manipulated in an experimental framework, a divergence of relative abundance trends between dingoes and foxes would be particularly strong evidence for mesopredator suppression or release. The corollary of this is that non-divergence of dingo and fox population trends over time would be particularly strong evidence that mesopredator suppression by dingoes is not occurring (e.g. Arthur et al., in press).

In summary, and additional to the methodological flaws described earlier, many studies are also conducted over small spatial and/or temporal scales (Table 2). This may taint the results with the sampling biases described, giving rise to potentially mistaken interpretations of inverse relationships between predators. The presence of this issue in the literature further weakens the reliability of data on dingoes' ecological roles and the perceptions based on them (Table 1). Overturning this conclusion for any given study requires demonstration that either (1) the study was not conducted over small spatial or temporal scales and/or (2) that if so, that the data were not biased, or that the bias was corrected for in subsequent analyses. Importantly however, inferences from such studies may be on solid ground provided they do not extend beyond the area or timeframe sampled, and acknowledgement of this limitation is also required of later reports or reviews citing such studies. Such biased data might only be suggestive of spatial avoidance between predators, but it cannot demonstrate avoidance, limitation, suppression or regulation. Provided the proper indexing principles are strictly applied and the data analysed appropriately, studies assessing predator population trends over 
longer timeframes will have a much better ability to reliably identify correlative relationships. However, to identify causal processes for observed correlations still requires experimental designs with even greater inferential ability.

\subsection{Experimental design constraints}

Poor application of methods and sampling bias are but two forms of experimental design constraints weakening the reliability of many dingo-related studies. But even if such issues are avoided through appropriate sampling strategies, different types of experimental designs have inherent limitations to their inferential ability (Platt, 1964; Hone, 2007). This is precisely the reason why Letnic et al. (2009b, p. 6) could "only speculate about the mechanisms that produced the patterns in abundance and species richness we observed", why Johnson and VanDerWal (2009, p. 645) could not "be certain of the mechanism producing the negative correlation of abundance" between dingoes and foxes, why Southgate et al. (2007a, p. 771) accepted that "inferential statistics do not permit us to specify the causal mechanisms that may be involved" in dingo-prey relationships, or why Wallach et al. (2009a, p. 48) concede that their "study does not prove the top predator hypothesis [but only] challenges the most notable cases that appeared to contradict it". In spite of these indispensible caveats, some have advocated that these and similar studies provide strong or "clear and consistent evidence" that lethal dingo control is linked with the mesopredator release of foxes and feral cats (e.g. Ritchie, 2010, p. 1 ). In stark contrast to such opinion, our critique demonstrates that the bulk of the literature on dingoes' ecological roles is 'as clear as mud', and with few exceptions (Table 2), might instead be viewed as a growing collection of consistently unreliable studies (see also Allen et al., 2011b). Overturning this conclusion for any given study requires showing that the experimental design used can reliably demonstrate causal relationships.

The implications of these design limitations have not been adequately dealt with in most appraisals of the literature on dingoes' ecological roles. In 2007, the review of Glen and colleagues concluded that the available data on dingoes' ecological roles was 'mostly observational' and correlative, and most relevant studies published since then (Table 2 ) have not improved this situation. It should be understood that "studies of a more observational nature can make only weak inferences about cause and effect and studies that involve classical experiments can make stronger inferences" and "where studies use more observational methods the results should be interpreted and valued as such, and not as equivalent to the results of classical experiments" (Hone, 2007, p. 13). The replication and randomisation of treatments, along with the use of nil-treatments (or experimental controls) are particularly important design features that can provide a greater ability to demonstrate causal processes (Platt, 1964), provided methodological flaws and sampling bias are also avoided.

The inferential capabilities of the different designs discussed in Hone (2007) were here ranked 1-16 in Table 2 (1 = highest level of inference, 16 = lowest). Without a nil-treatment, the highest rank a study can achieve is a pseudo-experiment type I (Rank 9). Without randomisation, the highest rank possible is a quasi-experiment type I (Rank 5). The latter is often unavoidable because the random allocation of treatments may not be possible for sites with a long history of a given land use, dingo management approach or otherwise. As Glen et al. (2007) forewarned, conducting randomised and replicated experiments on dingoes at sufficient spatial and temporal scales is costly and logistically difficult. We hasten to add, however, that they are achievable.

Our comprehensive review detected only the study of Allen (2012b) to have undertaken a classical experiment on dingoes, where randomly allocated treatments and nil-treatment areas were also replicated (two of each in one of three study areas). Three other true experiments were similarly conducted without replication (i.e. Allen et al., 1998; Allen, 2005; Eldridge et al., 2002). We note that the research described in Kennedy et al. (2012) is also derived from a true experiment conducted in a way that avoids the methodological flaws and sampling biases described earlier, but that these data were reduced to correlative analyses in the published report (Table 2). If analysed differently, data from Kennedy et al. (2012) might be considered a fifth study to provide demonstrable support for dingoes' ecological roles. Thus, almost all of the presently available literature on dingo-mesopredator interactions reports results from correlative designs (or lower) that simply cannot demonstrate causal mechanisms for observed relationships between predators and/or prey.

\section{Dingo predation risks to threatened fauna}

That dingoes provide widespread net benefits to biodiversity has been almost universally accepted (Table 1; but see also Bowman, 2012; Carwardine et al., 2011; Letnic et al., 2012b; Ritchie et al., 2012) despite the unreliable and inconclusive state of the literature (Section 4). A similar situation exists for wolves in north America (Mech, 2012). Additionally, and disregarded by most 'pro-dingo' studies is that dingoes have been implicated in the extinctions of native vertebrates prior to European settlement (e.g. Archer, 1974; Baird, 1991; Johnson, 2006) and the loss of other native vertebrates in the recent past (e.g. Allen, 2011; Corbett, 2001b; Horsup, 2004; Kerle et al., 1992; Moseby et al., 1998). For example, Moseby et al. (2011) reported that one individual dingo in a dingo-controlled area was responsible for the surplus killing of 14 (out of 101) reintroduced burrowing bettongs Bettongia lesueur on the first night after release (detected only by post-mortem evidence on killed animals), the rest succumbing to predation by unidentified predators within a few months. Indeed, many such populations of reintroduced threatened fauna only persist on islands or within reserves fenced to exclude dingoes and other eutherian predators (Moseby et al., 2011; Van Dyck and Strahan, 2008).

Predation by dingoes and other wild-living Canis sp. has therefore been identified as a known or potential threat in no less than 14 national threatened species recovery plans listed by the Australian government (Allen and Leung, 2012). 'Predation and hybridisation by feral dogs (Canis lupus familiaris)' is also a listed Key Threatening Process for 'threatened species, populations, and communities' in the state of New South Wales (see Major, 2009 for the listing, see Corbett, 2001a and Stephens, 2011 for the distribution of Canis sub-species in Australia, and see Allen et al., 2011b; Coman and Jones, 2007; Jones, 2009; Corbett, 2001b, 2008; Claridge and Hunt, 2008; Fleming et al., 2012 for discussion of taxonomy and functional similarities between free-roaming Australian sub-species of Canis). Dingoes also threaten northern hairy-nosed wombats (Lasiorhinus krefftii Banks et al., 2003; Horsup, 2004), bridled nailtail wallabies (Onychogalea fraenata Augusteyn et al., 2010; Lundie-Jenkins and Lowry, 2005) and a range of other species (Allen and Fleming, 2012; Coutts-Smith et al., 2007; Newsome et al., 1997; Newsome, 2011) in other areas, where it is predicted that some populations (such as those of koalas Phascolarctos cinereus; Lunney et al., 2007; Mifsud, 2011) will only persist through the control or absence of canid predators, including dingoes. Dingoes also transmit parasites and pathogens which can subsequently cause the decline of mammalian prey and exacerbate predation (e.g. Barnes et al., 2008).

Not only are many mammals susceptible to exploitation by dingoes, but some bird (e.g. Benshemesh, 2007; Boland, 2004; Corbett, 2001b) and reptile (e.g. Heard et al., 2006; Newsome, 2011; Som- 
aweera et al., 2011; Whiting et al., 2007) populations may also be substantially impacted by them. Applying established predation risk assessment methods developed for foxes and cats (see Dickman et al., 2009), Allen and Fleming (2012) showed that up to $94 \%$ of extant threatened mammals, birds and reptiles in western New South Wales could be at risk of dingo predation (71\% at high risk) should dingoes re-establish there under present conditions. By comparison, only $66 \%$ and $81 \%$ were predicted to be at risk of cat and fox predation using the same risk assessment approach (Dickman et al., 2009). Dingo predation of typically less-preferred taxa such as birds or reptiles may increase if preferred mammals become increasingly unavailable (Allen and Fleming, 2012).

Information on prey important to dingoes seems particularly useful for gauging the potential risks dingoes pose to threatened fauna. While the mere presence of threatened species in dingo diets might be dismissed as uncommon events, dingoes cannot eat what is not there, and 71\% (33 of 47) of dingo diet studies assessed $<500$ scat or stomach samples (Allen and Leung, 2012). Greater sampling effort and a consideration of additional information has highlighted substantial risks to threatened fauna from dingoes in some cases. For example, threatened mammals under $35 \mathrm{~g}$ body weight are typically considered to fall outside the primary weight-range of preferred prey for dingoes (Corbett, 2001b), but Newsome (2011; $N=1907$ scats) showed that anthropogenic provision of virtually unlimited food and water resources can exacerbate the risk of local decline for some such species by facilitating elevated levels of dingo predation on them (i.e. hyperpredation). In another example, Allen and Leung (2012; $N=4087$ scats) reported that although small rodents featured relatively infrequently in dingo scats while rabbits (Oryctolagus cuniculus) or kangaroos (Macropus spp.) were available, consideration of dingo predation rates on rodents (made possible by knowledge of predator and prey densities) supported earlier assertions by Newsome and Corbett (1975) that dingoes alone have the capacity to exterminate some rodent populations within a few months under certain conditions (e.g. dusky hopping-mice Notomys fuscus), regardless of any indirect benefit rodents might derive through dingoes' effects on foxes and/or cats. Even seemingly unsusceptible arboreal and fossorial species can become important prey for dingo populations following the decline of their preferred prey (Allen et al., 2012b; $N=1460$ scats).

It might be argued that predation from any source is likely to significantly inhibit recovery of small and critically endangered populations, and that common species might not be at risk of decline from dingo predation. However, native thylacines (Thylacinus cynocephalus), Tasmanian devils (Sarcophilus harrisii), or kangaroos, and introduced pigs (Sus scrofa), rabbits, foxes or cats are (or were once) common and widely distributed across mainland Australia, yet, in association with other factors (such as changed fire regimes, habitat fragmentation and pastoralism), populations of each of these species were (or are supposed to become) dramatically suppressed by dingoes (e.g.Caughley et al., 1980; Johnson, 2006; Letnic et al., 2012a,b; Wallach et al., 2010). Hence, why should we expect that only tiny populations will be impacted by dingoes? That dingoes can suppress overabundant and widely distributed species (e.g. foxes, cats and kangaroos) is precisely the reason why the positive management of dingoes is advocated in the first place (e.g. Johnson, 2006; Ritchie et al., 2012), and it would be unreasonable to expect that dingoes would exert this influence over their competitors but not their prey (Fleming et al., in press). Dingoes have the capacity to suppress and potentially threaten populations of fauna that are either common or rare and native or introduced under present or future ecological conditions. In any event, the risk of predators to prey populations is a function of prey species' rates of increase, not population size; for if recruitment remains less than attrition and this deficit is maintained, a population will eventually become extinct regardless of its starting size (Caughley and Sinclair, 1994).

Although we have outlined the direct risks dingoes pose to some threatened fauna, we note in passing that dingo predation also has the capacity to completely decimate farmed sheep (e.g. Allen and West, in press; Thomson, 1984) and goats (e.g. Allen et al. 1998, 2012b), whose food and fibre products (e.g. meat and wool) are locally, nationally and globally important commodities (see www.fao.org for details) expected to become even more important into the future (e.g. Thornton, 2010). Hence, similar to Mech (2012), we assert that the overriding economic, environmental and social costs of positive dingo management outside of conservation reserves may be more than many Australians are presently prepared to bear (Fleming et al., 2012). We also acknowledge that not all of the studies reporting negative impacts of dingoes on populations of threatened native fauna provide conclusive data for those impacts either. But given the wide variety of threatened fauna which appear in dingo diets and are known or expected to be negatively impacted by dingoes, we consider it prudent not to be so cavalier in advocating the positive management of dingoes to somehow 'protect' these and other native fauna.

Despite the unappreciated legitimacy of serious dingo predation risks to threatened native fauna, which must not be overlooked, there is some robust information (not reliant on passive tracking indices) to suggest that dingoes can sometimes perform positive roles in certain situations. In the only dingo introduction experiment ever conducted, Allen et al. (1998); but see also Allen et al. (2012b) demonstrated that a founder population of 16 mixed-gender and captive-raised or -bred dingoes rapidly exterminated $\sim 3000$ feral goats from a $70 \mathrm{~km}^{2}$ offshore island after release, with equally dramatic positive responses of vegetation to the subsequent absence of herbivory. In another study, economic modelling of empirical data has suggested that relaxation of lethal dingo control leads to dingo suppression of kangaroos (which compete with beef cattle for limited pasture) in arid areas, which can then facilitate sustainably higher stocking of cattle to a far greater degree than attempts to mitigate the occasional cattle predation losses dingoes impose by lethally controlling them (Wicks and Allen, 2012); a win-win for both livestock producers and dingo conservationists operating in such areas. The results of this modelling are supported by experimental data from other land systems demonstrating the numerical release of kangaroos following commencement of intensive lethal dingo control (Allen, 2005). In a $37 \mathrm{~km}^{2}$ pen study were individual GPS-collared foxes and cats were pitted against a pair of translocated dingoes and their pup, Moseby et al. (2012) also demonstrated that dingoes do kill foxes and feral cats, but that they could not exclude them from the pen, as other foxes and cats continued to invade from outside the 'predator proof' fenced area. These studies suggest that if dingoes are to have widespread and net ecological benefits, then these are most likely to be achieved through suppression of large herbivores (i.e. kangaroos and small ruminant livestock) and not through suppression of mesopredators (Allen, 2012b, 2005). Unfortunately, most of the studies investigating the potential ecological benefits of dingoes have focused on dingo-mesopredator interactions and not dingo-herbivore interactions (Allen et al., 2012a).

\section{Final remarks}

Our critical review of the empirical data underpinning knowledge of dingoes' ecological roles has shown that although dingoes may be well studied, their functional roles are not well understood or supported by conclusive data. Hence, many of the conclusions drawn by authors and readers (Table 1 ) are open to mixed and conflicting plausible interpretations. This is possible because the 
methodological flaws, sampling bias, and experimental design limitations inherent to most studies (Table 2) do not permit reliable or conclusive evidence for dingoes' ecological roles - whatever they are. Moreover, because the four true experiments may not be easily detected in literature searches (being a PhD thesis, a book chapter, and two government technical reports), it is noteworthy that not one of the perceptions advanced in Table 1 are based on results from any of these experiments, but instead have their genesis in popular correlative and observational reports. These results lead us to agree with Glen (in press) that cessation of lethal dingo control is presently unjustified on biodiversity protection grounds.

This conclusion was previously advanced by Allen et al. (2011a), but that review stirred much debate (described earlier), partly fuelled and perpetuated by misunderstandings and misrepresentations of their conclusions (e.g. Johnson and Ritchie, in press). As this critical review substantially expands on the scope of Allen et al. (2011a), we seek to be clear on a few points (individually identified in Table 2):

- First, we claim that multiple studies have made invalid assumptions and/or comparisons between seasons or habitats. Such studies may offer unreliable results because spatiotemporal behavioural variability can confound relative abundance estimates of dingoes and other species (Engeman, 2005).

- Second, and regardless of the first point, we claim that multiple studies were conducted over small spatial and/or temporal scales. Such studies may offer unreliable results because the data may be biased towards the detection of dingoes (Mahon et al., 1998) and subsequent inferences of apparent inverse relationships between sympatric predators. Indeed, the greater the effect of dingoes on mesopredators is expected to be, the greater the likelihood that the results of small-scale studies are an artefact of such bias.

- Third, and regardless of the previous two points, we claim that the inherent inferential limitations of the various experimental designs employed preclude conclusive statements about causal factors for almost all studies assessed. Excluding the four true experiments, all other studies - being correlative or observational - simply cannot hope to offer demonstrable data regarding cause and effect (Hone, 2007).

Thus, we cannot avoid the conclusion that the data available in most studies of dingoes' ecological roles are at worst 'misleading' (Allen, 2010) and at best 'mostly observational' and correlative (Glen et al., 2007). At present, the available literature derived from passive tracking indices might simply be deemed 'unreliable' (Allen et al., 2011a) or 'inconclusive' (this study). Studies based on other types of dingo population indices are prone to similar issues (Allen, 2012c; but see Wallach et al., 2009b, Brook et al., 2012 or Wang and Fisher, 2012 for examples).

It appears, then, that there is an increasing trend towards the publication of unreliable studies claiming to provide evidence for the positive ecological roles of dingoes (Table 2), and that science may be in danger of sanctifying both wolves and dingoes (Allen et al., 2012a; Mech, 2012). So long as the production of this type of research continues, our knowledge of dingoes' ecological roles will be no further advanced in the future. This increasing publication of falsely positive findings may be considered an ecological example of the 'creeping crack of bias' described by Sarewitz (2012; but see also Ioannidis, 2005), which has the potential to erode public trust in top-predator research (and researchers) as a whole. Reducing the academic and public hype surrounding the utility of large canids as biodiversity conservation tools (Table 1) may be one way of addressing this pervasive problem (Sarewitz, 2012). Undertaking more robust inductive experiments which ad- dress and then exclude alternative hypotheses may be another (Platt, 1964).

Although studies with strong inferential ability are very valuable, studies not permitting strong inference are still an important part of the adaptive process of distinguishing credible from incredible patterns in nature (Holling and Allen, 2002; O'Donohue and Buchanan, 2001). With 'the cycle of adaptive inference' in mind (sensu Holling and Allen, 2002), reflection on the type of data available (Table 2) indicate that there are now sufficient observational studies and correlative tests of the dingo-mesopredator patterns observed to warrant the mandatory consideration of top-down effects in any investigation of threatened fauna population dynamics (Estes et al., 2011). Formulation of hypotheses has occurred (e.g. the status of threatened fauna is primarily related to dingo suppression of mesopredators; e.g. Johnson et al., 2007), and given omissions and inconsistencies in the patterns observed, alternative competing hypotheses have been advanced (e.g. the status of threatened fauna is primarily related to the cumulative effects of livestock grazing; e.g. Allen, 2011). Thus, knowledge of dingoes' roles has arrived at the point where manipulative experiments are needed to distinguish between competing hypotheses, before repeating the adaptive process again.

We are mindful that questioning the conclusions of studies documenting the benefits of fox control on native fauna (e.g. Hone, 1999) probably delayed the necessary implementation of broadscale fox control for biodiversity conservation in many places. Likewise, we acknowledge that demonstrating the unreliability and inconclusiveness of the available science underpinning the ecological roles of dingoes may delay the adoption of positive dingo management in places that might yet be shown to need it. We encourage the continued interest in dingoes as one of several potential biodiversity conservation tools. However, we assert that the presently available evidence in support of positive dingo management is weak, and there are also sufficient concerns regarding the negative impacts of dingoes on threatened fauna (and other economic and social values) to merit strong caution when considering the positive management of dingoes for biodiversity conservation purposes in the clear absence of supporting data.

\section{Acknowledgements}

We sincerely thank Dr. Matt Hayward from Australian Wildlife Conservancy for his idea to include consideration of sampling bias, for his substantial input into Section 4.2 and the manuscript as a whole, and for his substantial contribution to Allen et al. (2012a), from which this report is derived. Jim Hone also provided helpful and constructive comments on earlier drafts of the manuscript, as did five anonymous reviewers. This research was carried out as part of work supported by the Invasive Animals Cooperative Research Centre, which contributed funds to support the involvement of Ben Allen, Guy Ballard and Peter Fleming.

\section{References}

Allen, B.L., 2010. Did dingo control cause the elimination of kowaris through mesopredator release effects? A response to Wallach and O'Neill (2009). Anim. Biodivers. Conserv. 32, 1-4.

Allen, B.L., 2011. A comment on the distribution of historical and contemporary livestock grazing across Australia: implications for using dingoes for biodiversity conservation. Ecol. Manage. Restor. 12, 26-30.

Allen, B.L., 2012a. Do desert dingoes drink daily? Visitation rates at remote waterpoints in the Strzelecki desert. Aust. Mammal. 34, 251-256.

Allen, B.L. 2012b. The effect of lethal control on the conservation values of Canis lupus dingo. In: Maia, A.P., Crussi, H.F. (Eds.), Wolves: Biology, Conservation, and Management. Nova Publishers, New York, pp. 79-108.

Allen, B.L., 2012c. Scat happens: spatiotemporal fluctuation in dingo scat collection rates. Aust. J. Zool. 60, 137-140.

Allen, B.L., Engeman, R.M., Allen, L.R., 2011a. Wild dogma I: an examination of 
recent "evidence" for dingo regulation of invasive mesopredator release in Australia. Curr. Zool. 57, 568-583.

Allen, B.L., Engeman, R.M., Allen, L.R., 2011b. Wild dogma II: the role and implications of wild dogma for wild dog management in Australia. Curr. Zool. 57, 737-740.

Allen, B.L., Fleming, P.J.S., 2012. Reintroducing the dingo: the risk of dingo predation to threatened vertebrates of western New South Wales. Wildlife Res. 39, 35-50.

Allen, B.L., Fleming, P.J.S., Hayward, M., Allen, L.R., Engeman, R.M., Ballard, G., Leung, L.K.-P., 2012a. Top-predators as biodiversity regulators: contemporary issues affecting knowledge and management of dingoes in Australia. In: Lameed, G.A. (Ed.), Biodiversity Enrichment in a Diverse World. InTech Publishing, Rijeka, Croatia, pp. 85-132.

Allen, B.L., Leung, L.K.-P., 2012. Assessing predation risk to threatened fauna from their prevalence in predator scats: dingoes and rodents in arid Australia. PLoS ONE 7, e36426.

Allen, B.L., West, P., in press. The influence of dingoes on sheep distribution in Australia. Aust. Veter. J.

Allen, L., Engeman, R., Krupa, H., 1996a. Evaluation of three relative abundance indices for assessing dingo populations. Wildlife Res. 23, 197-206.

Allen, L., Lee, J., Gonzalez, A., 1998. The Management and Eradication of Feral Goats from Townshend Island. Final report to Department of Defence. Department of Natural Resources, Toowoomba.

Allen, L.R., 2005. The Impact of Wild Dog Predation and Wild Dog Control on Beef Cattle Production. PhD Thesis, Department of Zoology, The University of Queensland, Brisbane.

Allen, L.R., 2006. Best-Practice Baiting: Evaluation of Large-scale, Community-based 1080 Baiting Campaigns. Robert Wicks Pest Animal Research Centre, Department of Primary Industries (Biosecurity Queensland), Toowoomba

Allen, L.R., 2009. Best practice baiting: dispersal and seasonal movement of wild dogs (Canis lupus familiaris). In: Technical Highlights: Invasive Plant and Animal Research 2008-09. QLD Department of Employment, Economic Development and Innovation, Brisbane, pp. 61-62.

Allen, L.R., 2012d. Interactions between Wild Dogs, Livestock Guardian Dogs and Wildlife. Final report to Bureau of Rural Sciences. Biosecurity Queensland, Toowoomba.

Allen, L.R., Fleming, P.J.S., Thompson, J.A., Strong, K., 1989. Effect of presentation on the attractiveness and palatability to wild dogs and other wildlife of 2 unpoisoned wild dog bait types. Aust. Wildlife Res. 16, 593-598.

Allen, L.R., Gonzalez, A., 2000. Movement of Dingoes from Shoalwater Bay Training Area. Final report to Department of Defence. Department of Natural Resources, Toowoomba.

Allen, L.R., Goullet, M., Palmer, R., 2012b. The diet of the dingo (Canis lupus dingo and hybrids) in north-eastern Australia: a supplement to Brook and Kutt. Rangeland J. 34, 211-217.

Allen, L.R., Lee, J., Edwards, J., 1996b. Managing feral goats and their impact on Townshend island in Shoalwater bay training area. In: Crabb, P., Kesby, J., Olive, L. (Eds.), Environmentally Responsible Defence. Australian Defence Studies Centre, The University of New South Wales, pp. 79-86.

Anderson, D.R., 2001. The need to get the basics right in wildlife field studies. Wildlife Soc. Bull. 29, 1294-1297.

Archer, M., 1974. New information about the quaternary distribution of the thylacine (Marsupialia, Thylacinidae) in Australia. J. Proc. Roy. Soc. West. Aust. 57, 43-50.

Arthur, A.D., Catling, P.C., Reid, A., In press. Relative influence of habitat structure, species interactions and rainfall on the post-fire population dynamics of ground-dwelling vertebrates. Aust. Ecol.

Atwood, T.C., Fry, T.L., Leland, B.R., 2011. Partitioning of anthropogenic watering sites by desert carnivores. J. Wildlife Manage. 75, 1609-1615.

Augusteyn, J.D., Hemson, G., Bennison, K.A., Allen, L.R., Wyland, J., Nolan, B.J., Kerr, R.J., 2010. Determining the effectiveness of canine control at Taunton National park (Scientific) and its impact on the population of bridled nailtail wallabies. In: Queensland Pest Animal Symposium. Gladstone, Queensland.

Baird, R.F., 1991. The dingo as a possible factor in the disappearance of the Gallinula mortierii from the Australian mainland. EMU 91, 121-122.

Banks, S.C., Horsup, A., Wilton, A.N., Taylor, A.C., 2003. Genetic marker investigation of the source and impact of predation on a highly endangered species. Mol. Ecol. $12,1663-1667$.

Barnes, T.S., Goldizen, A.W., Morton, J.M., Coleman, G.T., 2008. Cystic echinococcosis in a wild population of the brush-tailed rock-wallaby (Petrogale penicillata), a threatened macropodid. Parasitology 135, 715-723.

Benshemesh, J., 2007. National Recovery Plan for Malleefowl. Department for Environment and Heritage, South Australia.

Boland, C.R.J., 2004. Breeding biology of rainbow bee-eaters (Merops ornatus): a migratory, colonial, cooperative bird. Auk 121, 811-823.

Bowman, D., 2012. Bring elephants to Australia? Nature 482, 30.

Brawata, R.L., Neeman, T., 2011. Is water the key? Dingo management, intraguild interactions and predator distribution around water points in arid Australia. Wildlife Res. 38, 426-436.

Brook, L.A., Johnson, C.N., Ritchie, E.G., 2012. Effects of predator control on behaviour of an apex predator and indirect consequences for mesopredator suppression. J. App. Ecol. 49, 1278-1286.

Burrows, N.D., Algar, D., Robinson, A.D., Sinagra, J., Ward, B., Liddelow, G., 2003. Controlling introduced predators in the Gibson desert of western Australia. J. Arid Environ. 55, 691-713.
Carwardine, J., O'Connor, T., Legge, S., Mackey, B., Possingham, H.P., Martin, T.G. 2011. Priority Threat Management to Protect Kimberley Wildlife. CSIRO Ecosystem Sciences, Brisbane.

Catling, P.C., Burt, R.J., 1995a. Studies of the ground-dwelling mammals of eucalypt forests in south-eastern New South Wales: the effect of habitat variables on distribution and abundance. Wildlife Res. 22, 271-288.

Catling, P.C., Burt, R.J., 1995b. Why are red foxes absent from some eucalypt forests in eastern New South Wales? Wildlife Res. 22, 535-546.

Catling, P.C., Hertog, A., Burt, R.J., Wombey, J.C., Forrester, R.I., 1999. The short-term effect of cane toads (Bufo marinus) on native fauna in the Gulf country of the northern territory. Wildlife Res. 26, 161-185.

Caughley, G., 1980. Analysis of Vertebrate Populations, Reprinted with Corrections John Wiley \& Sons Ltd., Chichester.

Caughley, G., Grigg, G.C., Caughley, J., Hill, G.J.E., 1980. Does dingo predation contro the densities of kangaroos and emus? Aust. Wildlife Res. 7, 1-12.

Caughley, G., Sinclair, A.R.E., 1994. Wildlife Ecology and Management. Blackwell Sciences, Cambridge, Massachusetts.

Christensen, P., Burrows, N., 1995. Project desert dreaming: experimental reintroduction of mammals to the Gibson desert, western Australia. In: Serena, M. (Ed.), Reintroduction biology of Australian and New Zealand fauna. Surrey Beatty \& Sons, Sydney, pp. 199-207.

Claridge, A., Hunt, R., 2008. Evaluating the role of the Dingo as a trophic regulator: additional practical suggestions. Ecological Management \& Restoration 9, 116119.

Claridge, A.W., Cunningham, R.B., Catling, P.C., Reid, A.M., 2010. Trends in the activity levels of forest-dwelling vertebrate fauna against a background of intensive baiting for foxes. For. Ecol. Manage. 260, 822-832.

Coman, B., Jones, E., 2007. The Loaded Dog: On Objectivity in the Biological Sciences and the Curious Case of the Dingo. Quadrant 1 November 2007.

Corbett, L., 1995. Does dingo predation or buffalo competition regulate feral pig populations in the Australian wet-dry tropics? An experimental study. Wildlife Res. 22, 65-74.

Corbett, LK, 2001a. The conservation status of the dingo Canis lupus dingo in Australia, with particular reference to New South Wales: threats to pure dingoes and potential solutions. In: Dickman, C.R., Lunney, D. (Eds.), Symposium on the Dingo. Royal Zoological Society of New South Wales, Australian Museum, Mossman, pp. 10-19.

Corbett, L.K., 2001b. The Dingo in Australia and Asia, second ed. J.B. Books, South Australia, Marleston.

Corbett, L.K., 2008. Canis lupus ssp. dingo. IUCN 2010. IUCN Red List of Threatened Species. Version 2010.4. <www.iucnredlist.org> (downloaded 20.04.11).

Courchamp, F., Langlais, M., Sugihara, G., 2000. Rabbits killing birds: modelling the hyperpredation process. J. Anim. Ecol. 69, 154-164.

Coutts-Smith, A.J., Mahon, P.S., Letnic, M., Downey, P.O., 2007. The Threat Posed by Pest Animals to Biodiversity in New South Wales. Invasive Animals Cooperative Research Centre, Canberra.

Dickman, C. Glen, A, Letnic, M., 2009. Reintroducing the dingo: can Australia's conservation wastelands be restored? In: Hayward, M.W., Somers, M.J. (Eds.), Reintroduction of Top-order Predators. Wiley-Blackwell, Oxford, pp. 238-269.

Edwards, G.P., de Preu, N., Crealy, I.V., Shakeshaft, B.J., 2002a. Habitat selection by feral cats and dingoes in a semi-arid woodland environment in central Australia. Aust. Ecol. 27, 26-31.

Edwards, G.P., Dobbie, W., Berman, D.M., 2002b. Population trends of European rabbits and other wildlife of central Australia in the wake of rabbit haemorrhagic disease. Wildlife Res. 29, 557-565.

Edwards, G.P., Dobbie, W., Berman, D.M., 2002c. Warren ripping: its impacts on European rabbits and other wildlife of central Australia amid the establishment of rabbit haemorrhagic disease. Wildlife Res. 29, 567-575.

Eldridge, S.R., Berman, D.M., Walsh, B., 2000. Field evaluation of four 1080 baits for dingo control. Wildlife Res. 27, 495-500.

Eldridge, S.R., Shakeshaft, B.J., Nano, T.J., 2002. The Impact of Wild Dog Control on Cattle, Native and Introduced Herbivores and Introduced Predators in Centra Australia. Final Report to the Bureau of Rural Sciences. Parks and Wildlife Commission of the Northern Territory, Alice Springs.

Engeman, R., 2005. Indexing principles and a widely applicable paradigm for indexing animal populations. Wildlife Res. 32, 202-210.

Engeman, R.M., 2003. More on the need to get the basics right: population indices Wildlife Soc. Bull. 31, 286-287.

Estes, J.A., Terborgh, J., Brashares, J.S., Power, M.E., Berger, J., Bond, W.J., Carpenter S.R., Essington, T.E., Holt, R.D., Jackson, J.B.C., Marquis, R.J., Oksanen, L., Oksanen, T., Paine, R.T., Pikitch, E.K., Ripple, W.J., Sandin, S.A., Scheffer, M., Schoener, T.W. Shurin, J.B., Sinclair, A.R.E., Soulé, M.E., Virtanen, R., Wardle, D.A., 2011. Trophic downgrading of planet earth. Science 333, 301-306.

Fillios, M., Gordon, C., Koch, F., Letnic, M., 2010. The effect of a top predator on kangaroo abundance in arid Australia and its implications for archaeological faunal assemblages. J. Archaeol. Sci. 37, 986-993.

Fleming, P.J.S., 1996. Aspects of the Management of Wild Dogs (Canis familiaris) in North-eastern New South Wales. Masters Thesis, The University of New England, Armidale.

Fleming, P.J.S., Allen, B.L., Ballard, G., 2012. Seven considerations about dingoes as biodiversity engineers: the socioecological niches of dogs in Australia. Aust Mammal. 34, 119-131.

Fleming, P.J.S., Allen, B.L., Ballard, G., in press. Cautionary considerations for positive dingo management: a response to the Johnson and Ritchie critique of Fleming et al. (2012). Aust. Mammal. http://dx.doi.org/10.1071/AM12036. 
Fleming, P.J.S., Thompson, J.A., Nicol, H.I., 1996. Indices for measuring the efficacy of aerial baiting for wild dog control in north-eastern New South Wales. Wildlife Res. 23, 665-674.

Glen, A.S., 2012. Enough dogma: seeking the middle ground on the role of dingoes. Curr. Zool. 58, 856-858.

Glen, A.S., Dickman, C.R., 2003. Effects of bait-station design on the uptake of baits by non-target animal during control programs for foxes and wild dogs. Wildlife Res. 30, 147-149.

Glen, A.S., Dickman, C.R., Soulé, M.E., Mackey, B.G., 2007. Evaluating the role of the dingo as a trophic regulator in Australian ecosystems. Aust. Ecol. 32, 492-501.

Hayward, M.W., Slotow, R., 2009. Temporal partitioning of activity in large African carnivores: tests of multiple hypotheses. S. Afr. J. Wildlife Res. 39, 109-125.

Heard, G.W., Robertson, P., Black, D., Barrow, G., Johnson, P., Hurley, V., Allen, G., 2006. Canid predation: a potentially significant threat to relic populations of the Inland Carpet Python Morelia spilota metcalfei (Pythonidae) in Victoria. Victorian Nat. 123, 68-74

Holling, C.S., Allen, C.R., 2002. Adaptive inference for distinguishing credible from incredible patterns in nature. Ecosystems 5, 319-328.

Hone, J., 1999. Fox control and rock-wallaby population dynamics - assumptions and hypotheses. Wildlife Res. 26, 671-673.

Hone, J., 2007. Wildlife Damage Control. CSIRO Publishing, Collingwood, Victoria.

Horsup, A., 2004. Recovery Plan for the Northern Hairy-nosed Wombat Lasiorhinus krefftii 2004-2008 Report Produced by the Environmental Protection Agency/ Queensland Parks and Wildlife Service for the Department of Environment and Heritage, Canberra.

Ioannidis, J.P.A., 2005. Why most published research findings are false. PLoS Med. 2 e124.

Johnson, C., 2006. Australia's Mammal Extinctions: A 50000 year History. Cambridge University press, Melbourne.

Johnson, C., VanDerWal, J., 2009. Evidence that dingoes limit the abundance of a mesopredator in eastern Australian forests. J. Appl. Ecol. 46, 641-646.

Johnson, C.N., Isaac, J.L., Fisher, D.O., 2007. Rarity of a top predator triggers continent-wide collapse of mammal prey: dingoes and marsupials in Australia. Proc. Roy. Soc. Biol. Sci. Ser. B 274, 341-346.

Johnson, C.N., Ritchie, E., in press. The dingo and biodiversity conservation: response to Fleming et al. (2012). Aust. Mammal. http://dx.doi.org/10.1071/ AM12005.

Johnson, D.H., 2008. In defense of indices: the case of bird surveys. J. Wildlife Manage. 72, 857-868.

Jones, E., 2009. Hybridisation between the dingo, Canis lupus dingo, and the domestic dog, Canis lupus familiaris, in Victoria: a critical review. Aust. Mammol. 31, 1-7.

Kennedy, M., Phillips, B., Legge, S., Murphy, S., Faulkner, R., 2012. Do dingoes suppress the activity of feral cats in northern Australia? Aust. Ecol. 37, 134-139.

Kerle, J.A., Foulkes, J.N., Kimber, R.G., Papenfus, D., 1992. The decline of the brushtail possum, Trichosurus vulpecula (Kerr 1798), in arid Australia. Rangeland J. 14, 107-127.

Koertner, G., Watson, P., 2005. The immediate impact of 1080 aerial baiting to control wild dogs on a spotted-tailed quoll population. Wildlife Res. 32, 673680.

Krebs, C.J., 2008. Ecology: The Experimental Analysis of Distribution and Abundance, sixth ed. Benjamin-Cummings Publishing, San Francisco.

Letnic, M., Crowther, M., Koch, F., 2009a. Does a top-predator provide an endangered rodent with refuge from a mesopredator? Anim. Conserv. 12, 302-312.

Letnic, M., Crowther, M.S., in press. Patterns in the abundance of kangaroo populations in arid Australia are consistent with the exploitation ecosystems hypothesis. Oikos. http://dx.doi.org/10.1111/j.1600-0706.2012.20425.x.

Letnic, M., Crowther, M.S., Dickman, C.R., Ritchie, E., 2011. Demonising the dingo: how much wild dogma is enough? Curr. Zool. 57, 668-670.

Letnic, M., Fillios, M., Crowther, M.S., 2012a. Could direct killing by larger dingoes have caused the extinction of the thylacine from mainland Australia? PLoS ONE 7, e34877.

Letnic, M., Koch, F., Gordon, C., Crowther, M., Dickman, C., 2009b. Keystone effects of an alien top-predator stem extinctions of native mammals. Proc. Roy. Soc. Lond. B 276, 3249-3256.

Letnic, M., Ritchie, E.G., Dickman, C.R., 2012b. Top predators as biodiversity regulators: the dingo Canis lupus dingo as a case study. Biol. Rev. 87, 390-413.

Levi, T., Wilmers, C.C., 2012. Wolves-coyotes-foxes: a cascade among carnivores. Ecology 93, 921-929.

Light, R.J., Singer, J.D., Willett, J.B., 1990. By Design: Planning Research in Higher Education. Harvard University, Boston, Massachusetts, USA

Lundie-Jenkins, G., Corbett, L.K., Phillips, C.M., 1993. Ecology of the rufous harewallaby, Lagorchestes hirsutus Gould (Marsupialia: Macropodidae), in the Tanami desert, northern Territory. III. Interactions with introduced mammal species. Wildlife Res. 20, 495-511.

Lundie-Jenkins, G., Lowry, J., 2005. Recovery Plan for the Bridled Nailtail Wallaby (Onychogalea fraenata) 2005-2009. Report to the Department of Environment and Heritage (DEH), Canberra. Environmental Protection Agency/Queensland Parks and Wildlife Service, Brisbane.

Lunney, D., Gresser, S., O'Neill, L.E., Matthews, A., Rhodes, J., 2007. The impact of fire and dogs on koalas at Port Stephens, New South Wales, using population viability analysis. Pac. Conserv. Biol. 13, 189-201.

MacKenzie, D.I., Nichols, J.D., Royle, J.A., Pollock, K.H., Bailey, L.L., Hines, J.E., 2006. Occupancy Estimation and Modelling: Inferring Patterns and Dynamics of Species Occurrence. Academic Press (Elsevier), London.
Mahon, P.S., Banks, P.B., Dickman, C.R., 1998. Population indices for wild carnivores: a critical study in sand-dune habitat, south-western Queensland. Wildlife Res. $25,11-22$.

Major, R., 2009. Predation and Hybridisation by Feral Dogs (Canis lupus familiaris) Key Threatening Process Listing. New South Wales Department of Environment, Climate Change, and Water, Sydney.

Mech, L.D., 2012. Is science in danger of sanctifying the wolf? Biol. Conserv. 150, 143-149.

Meek, P.D., Ballard, G., Fleming, P.J.S., 2012. An Introduction to Camera Trapping for Wildlife Surveys in Australia. PestSmart Toolkit Publication, Invasive Animals Cooperative Research Centre, Canberra, Australia.

Mifsud, G., 2011. Hansard Excerpt of the Transcript from the Commonwealth Senate Enquiry into the Status, Health and Sustainability of Australia'a Koala Population, 19 May 2011. Official Committee Hansard, The Commonwealth of Australia, Canberra.

Mifsud, G., Woolley, P.A., 2012. Predation of the Julia Creek dunnart (Sminthopsis douglasi) and other native fauna by cats and foxes on Mitchell grass downs in Queensland. Aust. Mammal. 34, 188-195.

Miller, B.J., Harlow, H.J., Harlow, T.S., Biggins, D., Ripple, W.J., 2012. Trophic cascades linking wolves (Canis lupus), coyotes (Canis latrans), and small mammals. Can. J. Zool. 90, 70-78.

Mitchell, B.D., Banks, P.B., 2005. Do wild dogs exclude foxes? Evidence for competition from dietary and spatial overlaps. Aust. Ecol. 30, 581-591.

Moseby, K., Read, J., Gee, P., Gee, I., 1998. A Study of the Davenport Range Blackfooted Rock Wallaby Colony and Possible Threatening Processes. Final report to Wildlife Conservation Fund. Department for Environment and Heritage, Adelaide.

Moseby, K.E., Neilly, H., Read, J.L., Crisp, H.A., 2012. Interactions between a top order predator and exotic mesopredators in the Australian rangelands. Int. J. Ecol., 15 pages. Article ID 250352.

Moseby, K.E., Owens, H., Brandle, R., Bice, J.K., Gates, J., 2006. Variation in population dynamics and movement patterns between two geographically isolated populations of the dusky hopping mouse (Notomys fuscus). Wildlife Res. 33, 223-232.

Moseby, K.E., Read, J.L., Paton, D.C., Copley, P., Hill, B.M., Crisp, H.A., 2011. Predation determines the outcome of 10 reintroduction attempts in arid south Australia. Biol. Conserv. 144, 2863-2872.

Newsome, A., Pech, R., Smyth, R., Banks, P., Dickman, C., 1997. Potential impacts on Australian native fauna of rabbit calicivirus disease. Biodiversity Group, Environment Australia, Canberra.

Newsome, A.E., Catling, P.C., Cooke, B.D., Smyth, R., 2001. Two ecological universes separated by the dingo barrier fence in semi-arid Australia: interactions between landscapes, herbivory and carnivory, with and without dingoes. Rangeland J. 23, 71-98.

Newsome, A.E., Catling, P.C., Corbett, L.K., 1983. The feeding ecology of the dingo. II. Dietary and numerical relationships with fluctuating prey populations in southeastern Australia. Aust. J. Ecol. 8, 345-366.

Newsome, A.E., Corbett, L.K., 1975. Outbreaks of rodents in semi-arid and arid Australia: causes, preventions, and evolutionary considerations. In: Prakash, I., Gosh, P.K., Dr., Junk, W. (Eds.), Rodents in Desert Environments. The Hague, The Netherlands.

Newsome, T.M., 2011. Ecology of the Dingo (Canis lupus dingo) in the Tanami Desert in Relation to Human-Resource Subsidies, PhD, The University of Sydney, Sydney.

O'Donohue, W., Buchanan, J.A., 2001. The weaknesses of strong inference. Behav. Philos. 29, 1-20

Pascoe, J.H., 2011. Apex Predators in the Greater Blue Mountains World Heritage Area. PhD, The University of Western Sydney, Sydney.

Pavey, C.R., Eldridge, S.R., Heywood, M., 2008. Population dynamics and prey selection of native and introduced predators during a rodent outbreak in arid Australia. J. Mammal. 89, 674-683.

Pettigrew, J.D., 1993. A burst of feral cats in the Diamantina: a lesson for the management of pest species? In: Siepen, G., Owens, C. (Eds.), Cat Management Workshop Proceedings. Queensland Department of Environment and Heritage, Brisbane, pp. 25-32.

Platt, J.R., 1964. Strong inference. Certain systematic methods of scientific thinking may produce much more rapid progress than others. Science 146, 347-353.

Pollock, K.H., 1995. The challenge of measuring change in wildlife populations: a biometrician's perspective. In: Grigg, G.C., Hale, P.T., Lunney, D. (Eds.), Conservation through the Sustainable Use of Wildlife. Centre for Conservation Biology, The University of Queensland, pp. 117-121.

Pollock, K.H., Nichols, J.D., Simons, T.R., Farnsworth, G.L., Bailey, L.L., Sauer, J.R. 2002. Large scale wildlife monitoring studies: statistical methods for design and analysis. Environmetrics 13, 105-119.

Purcell, B.V., 2009. Order in the pack: Ecology of Canis lupus dingo in the southern Greater Blue Mountains World Heritage Area. PhD, University of Western Sydney, School of Natural Sciences, Sydney.

Ramesh, T., Kalle, R., Sankar, K., Qureshi, Q., 2012. Spatio-temporal partitioning among large carnivores in relation to major prey species in Western Ghats. J. Zool. 287, 269-275.

Read, J., Eldridge, S., 2010. An optimised rapid detection technique for simultaneously monitoring activity of rabbits, cats, foxes and dingoes in the rangelands. Rangeland J. 32, 389-394.

Reddiex, B., Forsyth, D.M., 2006. Control of pest mammals for biodiversity protection in Australia. II. Reliability of knowledge. Wildlife Res. 33, 711-717. 
Reddiex, B., Forsyth, D.M., McDonald-Madden, E., Einoder, L.D., Griffioen, P.A., Chick, R.R., Robley, A.J., 2006. Control of pest mammals for biodiversity protection in Australia. I. Patterns of control and monitoring. Wildlife Res. 33, 691-709.

Ripple, W.J., Beschta, R.L., 2012. Trophic cascades in yellowstone: the first 15 years after wolf reintroduction. Biol. Conserv. 145, 205-213.

Ritchie, E., 2010. Dingoes: managing for ecosystem resilience and pastoral productivity. In: Queensland Pest Animal Symposium, Gladstone.

Ritchie, E.G., Elmhagen, B., Glen, A.S., Letnic, M., Ludwig, G., McDonald, R.A., 2012. Ecosystem restoration with teeth: what role for predators? Trends Ecol. Evol. $27,265-271$.

Sarewitz, D., 2012. Beware the creeping cracks of bias. Nature 485, 149.

Saunders, G., McLeod, L., 2007. Improving fox management strategies in Australia. Bureau of Rural Sciences, Canberra.

Somaweera, R., Webb, J.K., Shine, R., 2011. It's a dog-eat-croc world: dingo predation on the nests of freshwater crocodiles in tropical Australia. Ecol. Res. 26, 957967.

Soulé, M.E., Estes, J.A., Miller, B., Honnold, D.L., 2005. Strongly interacting species: conservation policy, management, and ethics. Bioscience 55, 168-176.

Southgate, R., Paltridge, R., Masters, P., Carthew, S., 2007a. Bilby distribution and fire: a test of alternative models of habitat suitability in the Tanami Desert, Australia. Ecography 30, 759-776.

Southgate, R., Paltridge, R., Masters, P., Ostendorf, B., 2007b. Modelling introduced predator and herbivore distribution in the Tanami desert, Australia. J. Arid Environ. 68, 438-464

Stephens, D., 2011. The Molecular Ecology of Australian Wild Dogs: Hybridisation, Gene Flow and Genetic Structure at Multiple Geographic Scales. PhD, The University of Western Australia, Perth.

Sutherland, W.J., 1996. Ecological Census Techniques. Cambridge University Press, Cambridge, UK.

Terborgh, J., Estes, J.A., 2010. Trophic Cascades: Predator, Prey, and the Changing Dynamics of Nature. Island Press, Washington, DC.
Thomson, P.C., 1984. Dingoes and sheep in pastoral areas. J. Agric. 25, 27-31.

Thomson, P.C., 1992. The behavioural ecology of dingoes in north-western Australia: IV. Social and spatial organisation, and movements. Wildlife Res. 19, 543-563.

Thornton, P.K., 2010. Livestock production: recent trends, future prospects. Philos. Trans. Roy. Soc. B 365, 2853-2867.

Van Dyck, S., Strahan, R. (Eds.), 2008. The Mammals of Australia, third ed. Reed New Holland, Sydney.

Visser, R.L., Watson, J.E.M., Dickman, C.R., Southgate, R., Jenkins, D., Johnson, C.N. 2009. Developing a national framework for dingo trophic regulation research in Australia: outcomes of a national workshop. Ecol. Manage. Restor. 10, 168-170.

Wallach, A.D., Johnson, C.N., Ritchie, E.G., O'Neill, A.J., 2010. Predator control promotes invasive dominated ecological states. Ecol. Lett. 13, 1008-1018.

Wallach, A.D., Murray, B.R., O'Neill, A.J., 2009a. Can threatened species survive where the top predator is absent? Biol. Conserv. 142, 43-52.

Wallach, A.D., O’Neill, A.J., 2009. Threatened species indicate hot-spots of top-down regulation. Anim. Biodivers. Conserv. 32, 127-133.

Wallach, A.D., Ritchie, E.G., Read, J., O'Neill, A.J., 2009b. More than mere numbers: the impact of lethal control on the stability of a top-order predator. PLoS ONE 4, e6861.

Wang, Y., Fisher, D., 2012. Dingoes affect activity of feral cats, but do not exclude them from the habitat of an endangered macropod. Wildlife Res. 39, 611-620.

Whiting, S.D., Long, J.L., Hadden, K.M., Lauder, A.D.K., Koch, A.U., 2007. Insights into size, seasonality and biology of a nesting population of the Olive Ridley turtle in northern Australia. Wildlife Res. 34, 200-210.

Wicks, S., Allen, B.L, 2012 Returns on Investment in Wild Dog Management: Beef Production in the South Australian Arid Lands. Australian Bureau of Agricultural and Resource Economics and Sciences, Department of Agriculture, Fisheries and Forestry, Canberra. 